\title{
ANALYSIS OF AN UNMITIGATED LARGE BREAK LOSS OF COOLANT ACCIDENT (LBLOCA) WITH THE NON-MECHANISTIC FAILURE OF PASSIVE COOLING FOR THE APT SPALLATION TARGET
}

Narinder K. Tutu, George A. Greene and Robert W. Youngblood

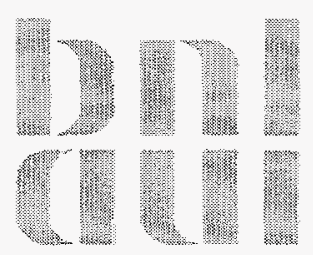

Manuscript Completed: December 1993

Department of Advanced Technology

BROOKHAVEN NATIONAL LABORATORY

ASSOCIATED UNIVERSITIES, INC.

UPTON, LONG ISLAND, NEW YORK 11973

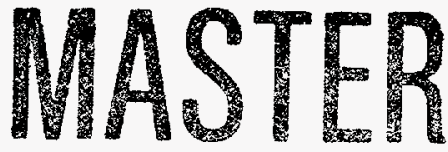

UNITED STATES DEPARTMENT OF ENERGY

CONTRACT NO DE-ACO2-76CH0OO16 


\section{DISCLAIMER}

This report was prepared as an account of work sponsored by an agency of the United States Government. Neither the United States Government nor any agency thereof, nor any of their employees, nor any of their contractors, subcontractors, or their employees, makes any warranty, express or implied, or assumes any legal liability or responsibility for the accuracy, completeness, or usefulness of any information, apparatus, product, or process disclosed, or represents that its use would not infringe privately owned rights. Reference herein to any specific commercial product, process, or service by trade name, trademark, manufacturer, or otherwise, does not necessarily constitute or imply its endorsement, recommendation, or favoring by the United States Government or any agency, contractor or subcontractor thereof. The views and opinions of authors expressed herein do not necessarily state or reflect those of the United States Government or any agency, contractor or subcontractor thereof.

Printed in the United States of America

Available from

National Technical Information Service

U.S. Department of Commerce

5285 Port Royal Road

Springfield, VA 22161

NTIS price codes:

Printed Copy: A03; Microfiche Copy: A01 


\section{DISCLAIMER}

Portions of this document may be illegible in electronic image products. Images are produced from the best available original document. 


\begin{abstract}
In order to support the Programmatic Environmental Impact Statement, an accident analysis has been performed for the APT SILC target. This report presents lumped-parameter calculations that predict the thermal response of the APT SILC source to a large-break LOCA. The accident scenario assumes the break to occur in the cold leg outside the source basin and the pipe break is immediately followed by the tripping of the proton beam and the activation of the source-basin flood system. The calculations were performed for a "beyond-design-basis event" which further assumes the failure of all other active cooling systems, and the failure to establish natural circulation in the unbroken loop.

Calculations show that the source rods remain flooded in heavy water until 44 hours after the LOCA. At this time, the source rods begin to be uncovered and at 48 hours into the accident the source rods are completely boiled dry. The average source temperature reaches a maximum value of $303{ }^{\circ} \mathrm{C}$ at 57 hours. Thereafter, the source rods begin to cool since the heat transfer to the basin water is sufficient to remove all the decay heat from the source. It is estimated that by this time a maximum of $27 \%$ of the lead inventory $(6558 \mathrm{~kg}$ ) in the source rods can be expected to melt. This molten material, assuming that it can get out of the aluminum cladding, will fall to the $\mathrm{D}_{2} \mathrm{O}$-filled bottom header, quench rapidly, and remain in a coolable state.
\end{abstract}


. 


\section{EXECUTIVE SUMMARY}

In order to support the Programmatic Environmental Impact Statement, an accident analysis has been performed for the Accelerator Production of Tritium (APT) Spallation-Induced Lithium Conversion (SILC) Source. This report presents a lumped-parameter analysis that predicts the thermal response of the source to a large-break LOCA.

It is assumed that a large double-ended pipe break occurs in a cold leg outside the source basin. This is immediately followed by a successful trip of the proton beam, tripping of Source Primary Coolant System (SPCS) pumps, and the activation of the source basin flood system. In order to be conservative, the accident scenario further assumes the simultaneous failure of all other (besides the Source Primary Coolant System) active cooling systems. Furthermore, for this "beyond-design-basis scenario," it is also postulated that no natural circulation in the unbroken loop (the second primary coolant system loop) is established following the LOCA.

After the SPCS pumps are tripped, internal inertial units within the pumps provide a 45-second coastdown period for both of the pumps. As the coolant leaks from the primary system through the break, the Accumulator and the Pressurizer begin to discharge their water inventories. Part of the Accumulator water discharged is circulated through the source pressure-tubes during the pump coastdown period. Since the decay heat at this time is only about $1 \%$ of normal power, the source rods actually cool during this pump coastdown period. It is calculated that at the end of the pump coastdown period (45 seconds), the source rods will cool to a temperature of $62.2^{\circ} \mathrm{C}$. After the pump coastdown flow has stopped, the source rods begin to heat up. At 90 seconds after LOCA, the average source temperature is calculated to be $65.5^{\circ} \mathrm{C}$. At this time, the source basin will also be completely flooded with water, thereby providing an additional heat sink for the removal of decay heat from the submerged source pressure-tubes.

After the basin is flooded with cold water, the following mechanisms for the heat transfer from the source rods to the water in the basin are considered. The source rods transfer heat to the pressuretubes via conduction and natural convection (natural convection within each pressure-tube, wherein the hot fluid from the central region rises upwards and the cold fluid along the walls of the cold pressure-tube moves downwards). The pressure-tubes, in turn, transfer energy to the basin water via natural convection.

Transient heat transfer calculations show that from 90 seconds to 1 hour, the source continues to cool. Subsequently, owing to the smaller temperature difference between the source and the basin water, the heat transfer to the basin water is no longer sufficient to remove all the decay heat from the source rods. Therefore, the source temperature begins to increase, and continues to increase until it reaches the $\mathrm{D}_{2} \mathrm{O}$ saturation temperature of $101.42^{\circ} \mathrm{C}$ at 22.8 hours. From this time onwards, the heavywater within the source begins to boil off. At 43.6 hours into the accident all of the $D_{2} \mathrm{O}$ inventory in the upper header of the source is boiled off and the source rods just begin to be uncovered. The heavywater adjacent to the source rods continues to boil, and at $\mathbf{4 8 . 4}$ hours the source rods in the pressuretubes are completely uncovered. Subsequently, the source rods begin to heat up rapidly. At 50.4 hours into the accident, calculations show that while the average source temperature reaches $218.7^{\circ} \mathrm{C}$, the centerline temperature in the pressure-tubes reaches the melting point of lead $\left(327.4^{\circ} \mathrm{C}\right)$. Therefore, from 
this time forward lead in the central regions of the pressure-tubes will begin to melt. The average source temperature continues to increase and reaches a maximum value of $302.9^{\circ} \mathrm{C}$ at 57.3 hours. Thereafter, the source rods begin to cool since the heat transfer to the basin water is sufficient to remove from the source all the decay heat that is being generated. Calculations show that by this time a maximum of 26.8 $\%$ of the lead inventory $(6557.7 \mathrm{~kg})$ in the source rods can be expected to have melted. Assuming that the aluminum encapsulation of the source rods does not contain the molten lead, this molten material will fall to the $\mathrm{D}_{2} \mathrm{O}$ filled bottom header, quench rapidly, and remain in a coolable state. Due to the design of the structures above the basin and the basin flood tank, all the steam produced due to the boiling of basin water is condensed and returned to the basin. Therefore, the basin will remain flooded. In addition, the calculations show that after 3 days, only $2854 \mathrm{~kg}$ ( $3.7 \%$ of the total inventory) of the basin water will have boiled off.

In spite of the very considerable conservatisms embedded in this analysis, the resulting accident is not particularly severe, owing to the capacity of the water in the system for absorbing the energy being released as decay heat. Related work has also shown that for this accident, a relatively insignificant radiological release is expected. 


\section{TABLE OF CONTENTS}

ABSTRACT $\ldots \ldots \ldots \ldots \ldots \ldots \ldots \ldots \ldots \ldots \ldots \ldots \ldots \ldots \ldots \ldots$

EXECUTIVE SUMMARY $\ldots \ldots \ldots \ldots \ldots \ldots \ldots \ldots \ldots \ldots \ldots \ldots$

LIST OF FIGURES $\ldots \ldots \ldots \ldots \ldots \ldots \ldots \ldots \ldots \ldots \ldots \ldots \ldots \ldots \ldots \ldots \ldots$

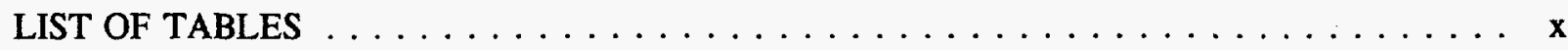

NOMENCLATURE $\ldots \ldots \ldots \ldots \ldots \ldots \ldots \ldots \ldots \ldots \ldots \ldots \ldots$

1. INTRODUCTION $\ldots \ldots \ldots \ldots \ldots \ldots \ldots \ldots \ldots \ldots \ldots \ldots \ldots$

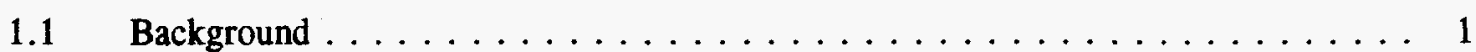

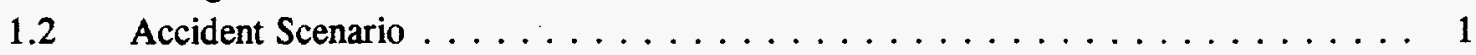

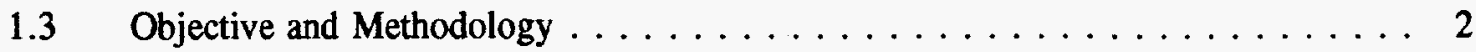

2. ANALYSIS OF THE SOURCE THERMAL RESPONSE $\ldots \ldots \ldots \ldots \ldots \ldots$

2.1 Time-Dependent Decay Heat Within the Source $\ldots \ldots \ldots \ldots \ldots$

2.2 Thermophysical Properties and the Initial

2.3 The Pump Coastdown Period $(0 \leq \mathrm{t} \leq 45 \mathrm{~s}) \ldots \ldots \ldots \ldots \ldots$

2.4 Source Heat-Up From the End of the Pump Coastdown Till the Basin is Flooded $(45<\mathrm{t} \leq 90 \mathrm{~s}) \ldots \ldots \ldots \ldots \ldots \ldots \ldots \ldots \ldots \ldots$

2.5 Source Heat-Up to Saturation With Flooded Source Basin $(t>90 \mathrm{~s}) \ldots \ldots$

2.5 .1 Introduction $\ldots \ldots \ldots \ldots \ldots \ldots \ldots \ldots$

2.5.2 Conduction Through a Long Circular Cylinder ... . . . . . . . . 9

2.5.3 Effective Thermal Conductivity of a Single Source Rod . . . . . . . . . 9

2.5.4 Effective Thermal Conductivity of Source Rods and the Surrounding Fluid Within a Pressure-Tube (Conduction Only) . . . . . . . . . 10

2.5.5 Effective Thermal Conductivity of Source Rods and the Surrounding Fluid Within a Pressure-Tube With Natural Convection Within the Pressure-Tubes ..................... 16

2.5.5.1 The case when pressure-tubes are full of (liquid) heavy water ...................... 16

2.5.5.2 The case when pressure-tubes are dry and filled with

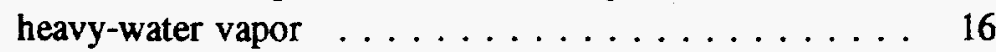

2.5.6 Heat Transfer From the Pressure-Tubes to the Basin Water . . . . . . . . 17

2.5.7 Energy Equations for the Source and the Basin Water . . . . . . . . . 19

2.6 Boil Off Half the Heavy-Water Inventory in the Top Header of the Source . . . 19

2.7 Drain the Unbroken Loop . . . . . . . . . . . . . . . . . . 20

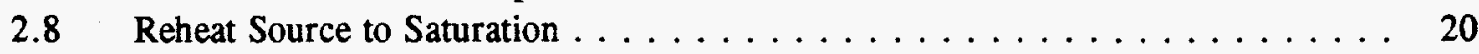

2.9 Boil off Heavy-Water in the Source Pressure-Tubes $\ldots \ldots \ldots \ldots \ldots$

2.10 Source Heat-Up Following Dry-Out $\ldots \ldots \ldots \ldots \ldots \ldots \ldots \ldots$

2.11 Estimation of the Mass of Molten Source-Rod Material Produced . . . . . . . . 24 
3. A SUMMARY OF THE SOURCE TEMPERATURE HISTORY $\ldots \ldots \ldots \ldots$

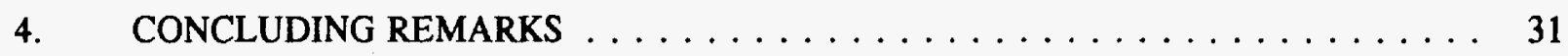

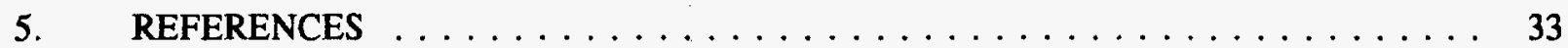




\section{LIST OF FIGURES}

Figure

Page

1. A schematic of the source and the Source Primary Coolant System (SPCS). . . . . . 3

2. A schematic of conduction through a heat generating cylinder. $\ldots \ldots \ldots \ldots$

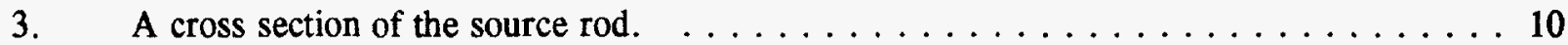

4. A cross section of a pressure-tube in Row $3 . \ldots \ldots \ldots \ldots \ldots \ldots \ldots$

5. A schematic of the center and the surrounding source rods. $\ldots \ldots \ldots \ldots \ldots$

6. Definition sketch for natural convection in a vertical cavity. $\ldots \ldots \ldots \ldots$

7. A schematic of temperature profile in the pressure-tube. $\ldots \ldots \ldots \ldots \ldots$

8. The calculated temperature history of the APT SILC source. . . . . . . . . . . 29 


\section{LIST OF TABLES}

Table

Page

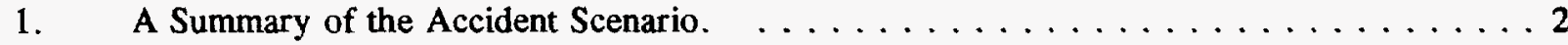

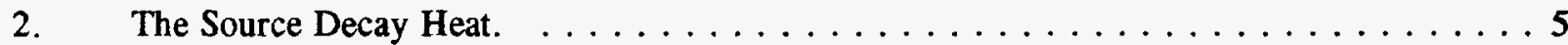

3. Thermophysical Properties of Aluminum, Lead, and $\mathrm{D}_{2} \mathrm{O}$ Used for the Calculations. . . 6 


\section{NOMENCLATURE}

A $\quad$ Total surface area of the source rods

$A_{w} \quad$ Total cross-sectional area for flow of heavy water through the source pressure-tubes

Bi Biot number [Equation (38)]

$c_{p} \quad$ Specific heat at constant pressure

$\mathrm{Cp}_{\mathrm{Pb}-\mathrm{Al}}$ Specific heat of the source rod

d Diameter of the source rod

D Diameter of the pressure-tube or a heat generating cylinder

g Acceleration due to gravity

Gr Grashof number [Equation (32)]

h Average heat-transfer coefficient $\left(\mathrm{W} / \mathrm{m}^{2} \mathrm{~K}\right)$

$h_{f g} \quad$ Latent heat of evaporation of water or heavy water

k Thermal conductivity

$k_{1} \quad$ Thermal conductivity of heavy water in the liquid phase

$\mathbf{k}_{\mathbf{8 r}} \quad$ Effective thermal conductivity of a single source rod

$k_{v} \quad$ Thermal conductivity of $\mathrm{D}_{2} \mathrm{O}$ vapor

L Length of source rods

$\mathscr{L}_{\mathbf{P b}} \quad$ Latent heat of fusion for lead

$\mathrm{m}_{\mathrm{bw}} \quad$ Mass of basin water boiled off

$m_{\mathrm{gw}} \quad$ Mass of source water boiled off

$\mathrm{Mcp}_{\mathrm{bw}}$ Total heat capacity of the basin water $(\mathrm{J} / \mathrm{K})$

$\mathrm{Mcp}_{\mathrm{ls}}$ Total heat capacity of the "lumped source" $=\mathrm{Mcp}_{\mathrm{r}}+\mathrm{Mcp}_{\mathrm{w}}(\mathrm{J} / \mathrm{K})$

$\mathrm{Mcp}_{\mathrm{r}}$ Total heat capacity of all the source rods $(\mathrm{J} / \mathrm{K})$ 
$\mathrm{Mcp}_{\mathrm{w}}$ Heat Capacity of $3010 \mathrm{~kg}$ of heavy water in the source $(\mathrm{J} / \mathrm{K})$

N Total number of pressure-tubes

$\mathrm{Nu} \quad$ Nusselt number $=\mathrm{h} \mathrm{W} / \mathrm{k}$

p Triangular pitch of the source rod matrix in the pressure-tube

Pr Prandtl number of the fluid $=\nu / \alpha$

q" Heat flux at the surface of source rods $\left(W / \mathrm{m}^{2}\right)$

$\mathrm{q}_{\mathrm{r}} \quad$ Decay power in a single source rod

Q Time dependent decay heat in the SILC source

$\mathrm{Q}_{\mathrm{basin}}$ Heat transfer rate from the pressure-tubes to the basin water

$\mathrm{Q}_{\mathrm{bt}} \quad$ Heat transfer rate from the source rods to the heavy water surface just below the source rods (following source rod dry-out)

Q"' Volumetric heat generation rate $\left(\mathrm{W} / \mathrm{m}^{3}\right)$

r Radial coordinate

$r_{\text {melt }} \quad$ Radius up to which the source rods will melt in the pressure-tube

$r_{m p} \quad$ Radius at which the local temperature in the pressure-tube is equal to the melting point of lead

$r_{\mathrm{s}}$ Radius at which the local temperature is equal to the average temperature in the pressure-tube

R Outer radius of a heat generating cylinder or a source pressure-tube

$R_{1} \quad$ Outer radius of the lead in the source rod

$\mathbf{R}_{2} \quad$ Outer radius of the aluminum cladding in the source rod

Ra Rayleigh number [Equation (34)]

t Time

T Temperature

$\mathrm{T}_{0} \quad$ Centerline temperature in a pressure-tube or a heat generating cylinder

$T_{R} \quad$ Wall temperature of the aluminum pressure-tube or temperature at $r=R$ 
$T_{8} \quad$ Average temperature of source rods or average temperature of "lumped source"

$\mathrm{T}_{\mathrm{wi}}$ Temperature of heavy water at the inlet of pressure-tubes

u Average velocity of coolant in the pressure-tubes

$\mathrm{V}_{\text {tube }}$ Total internal volume of the pressure-tubes in the region of the source rods

W Horizontal distance between two isothermal vertical surfaces

\section{Greek Letters}

$\alpha \quad$ Thermal diffusivity of the fluid

$\beta \quad$ Coefficient of thermal expansion for the fluid

$\delta \quad$ Twice the minimum distance between adjacent source rods $=2(p-d)$

$\nu \quad$ Kinematic viscosity of the fluid

\section{Subscripts}

Al Aluminum

bt Water interface below the source rods in the pressure-tubes after the source rods are boiled dry

$\mathrm{Pb} \quad$ lead

eff effective

w water or basin water

ws water surface 


\section{INTRODUCTION}

\subsection{Background}

The purpose of this report is to document the calculations used to predict the thermal response of the Accelerator Production of Tritium (APT) Spallation-Induced Lithium Conversion (SILC) Source to a large-break loss-of-coolant accident (LOCA). The "source" consists of an array of aluminum-clad lead rods held inside heavy-water cooled pressure-tubes. During normal operation, neutrons are produced within the source rods via spallation reactions induced by the incident beam of high energy protons. In all, the source consists of 33 pressure-tubes arranged in five rows. The heat generated in the source is removed by the circulating heavy water through the pressure-tubes. Two independent loops for the circulation of coolant through the pressure-tubes are provided. A schematic of the source and the Source Primary Coolant System (SPCS) is shown in Figure 1. This figure also shows the location of the large break in the cold leg that will be assumed in this analysis. As indicated in this figure, the source resides in an enclosure called the "source basin." During normal operation, the source basin is dry. However, a "source basin flood system" is designed to flood the source basin with water within 90 seconds following a LOCA.

\subsection{Accident Scenario}

It is assumed that at time $t=0$, a large double-ended pipe break occurs in a cold leg outside the source basin. This is immediately followed by a successful trip of the proton beam, tripping of SPCS pumps, and the activation of the source basin flood system. After the pumps are tripped, internal inertial units within the pumps provide a 45-second coastdown period for both of the pumps. As the coolant leaks from the primary system through the break, the Accumulator and the Pressurizer begin to discharge their water inventories. The coolant (heavy water) leaks from both ends of the break. The water discharged from the pressurizer flows directly through one end of the break without passing through the source. Part of the discharged Accumulator water is circulated through the source pressure-tubes during the pump coastdown period, and the remaining flow is discharged from the other side of the break in the cold leg via the bottom header of the source.

During normal operation, the power dissipated within the source is $168 \mathrm{MW}$. After the proton beam is tripped, the heat generated within the source is solely due to the time-dependent decay heat. The decay heat at the instant of the beam trip is about $1 \%$ of the normal operating power. At time $t=45$ seconds the pumps will have completely stopped, and at $t=90$ seconds the source basin will be flooded with water. In this accident scenario, to be conservative, it is further assumed that all the other active cooling systems fail. These are: (a) the "Source Residual Primary Cooling System (SRPCS)" consisting of two loops with a heat removal capacity of $1 \mathrm{MW}$ each, (b) the source basin heat exchanger system which is designed to remove up to $1 \mathrm{MW}$ from the water in the flooded basin, (c) the "Blanket Primary Cooling System (BPCS)" which would also be submerged in the flooded basin, and (d) the "Window Primary Cooling System (WPCS)" consisting of two loops with a capacity of $0.5 \mathrm{MW}$ each. For simplicity, these systems are not shown in Figure 1. Detailed information on the design of the APT SILC system is given in reference [1].

At the end of the pump coastdown period (45 seconds), the (primary cooling system) loop with 
the break will drain to the height of the break in the cold leg. However, due to the partial vacuum in the accumulator, the second loop (the loop on the left-hand side in Figure 1) will remain full of water. Thus as the source heats up, following the end of the pump coastdown, natural circulation may be established in the unbroken loop, thereby providing an additional mechanism for decay-heat removal. However, no analysis of the heat removal capability of this system, due to natural circulation in the unbroken loop, has been performed to date. In order to obtain a more bounding source term, we shall further assume that no natural circulation is established in the unbroken loop. At 90 seconds into the accident the source basin will be completely flooded with water, thereby providing a sink for the decay heat generated within the source rods. This accident scenario, which is analyzed in the next chapter, is summarized in Table 1.

Table 1. A Summary of the Accident Scenario.

\begin{tabular}{|c|c|}
\hline Time, $t$ (seconds) & Event Description \\
\hline$t=0$ & Large-break LOCA in Cold Leg Outside the Source Basin \\
\hline$t=0^{+}$ & $\begin{array}{ll}\text { - Trip Proton Beam } \\
\text { - Trip SPCS Pumps } \\
\text { - Signal Source Basin Flood System to Drain }\end{array}$ \\
\hline $0<\mathrm{t} \leq 45$ & $\begin{array}{ll}\text { - } & \text { Pumps Coastdown } \\
\text { - } \quad \text { Pressurizer and Accumulator Drain } \\
\text { - Source Over-cools (Heat Removal Exceeds Heat Generation) }\end{array}$ \\
\hline $45<\mathrm{t} \leq 90$ & $\begin{array}{l}\text { Assume All Active Cooling Systems Fail } \\
\text { Assume Source Basin is Dry } \\
\text { - Source Coolant Flow Stagnates } \\
\text { Source and Coolant Heat Up Adiabatically }\end{array}$ \\
\hline$t>90$ & $\begin{array}{l}\text { Source Basin is Flooded With Water } \\
\text { No Natural Circulation in the Unbroken Loop } \\
\text { Heat Transfer From the Source Rods to } \mathrm{D}_{2} \mathrm{O} \text { in the Source } \\
\text { Heat Transfer From the Pressure-Tubes to the Basin Water }\end{array}$ \\
\hline
\end{tabular}

\subsection{Objective and Methodology}

In order to evaluate the environmental impact of the accidents in the APT SILC Target, it is necessary to quantify any radioactive releases that may occur during "design basis" and "beyond design basis" events. Since radioactive releases are dependent upon the temperature history of the target and the mass of any molten material generated, this necessitates the prediction of the thermal response of the APT SILC system during these events. Therefore, the purpose of the calculations presented in this report was to predict the thermal response of the APT SILC target during the above-discussed accident scenario so that useful estimates of any radioactive releases could be made. 


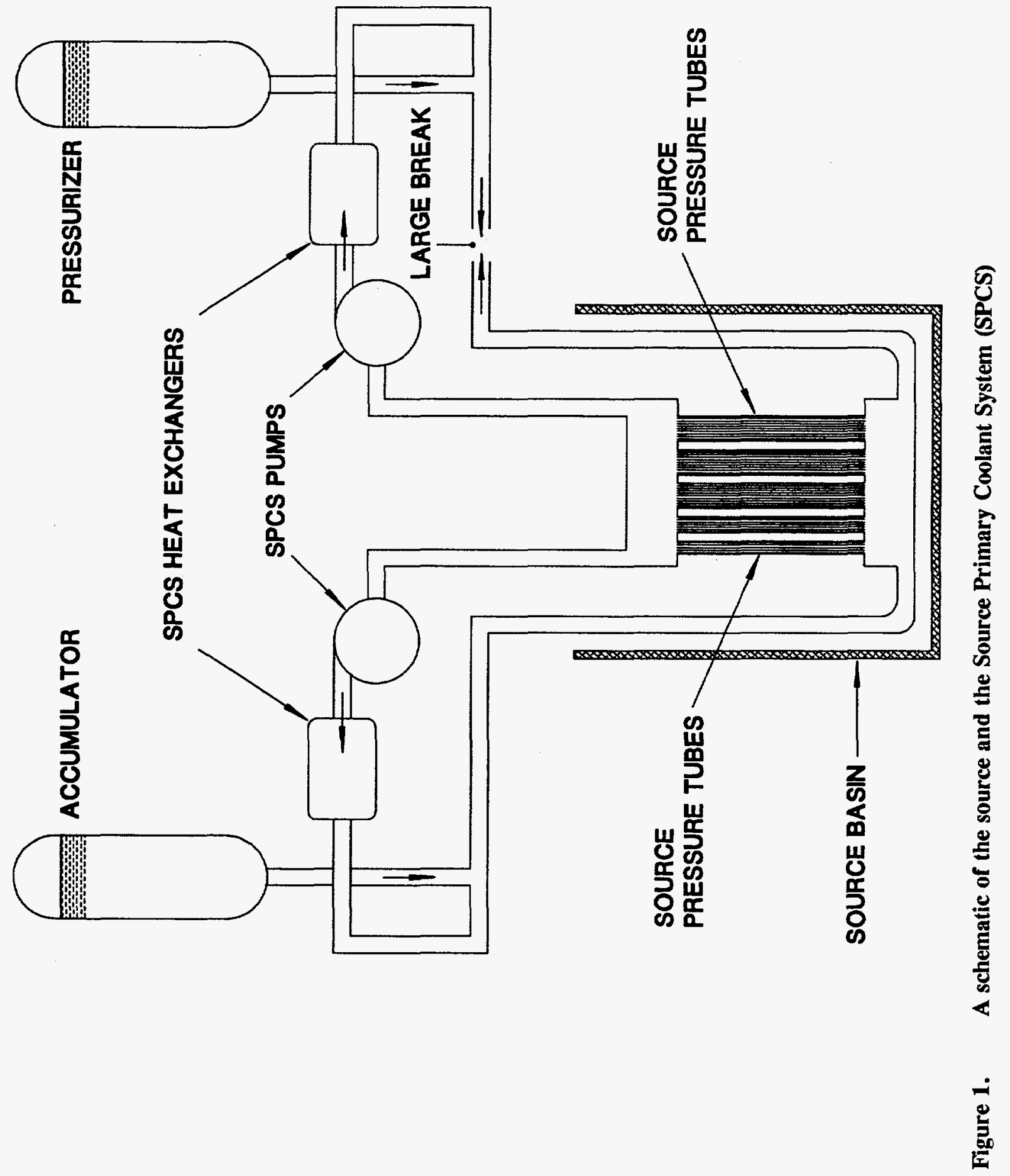


The APT SILC system is a complex thermal-hydraulic system. Therefore, it is necessary to make simplifying assumptions. In addition, in view of the extremely limited resources allocated to this task, assumptions about heat-transfer correlations for geometries for which no experimental data or correlations are available, also need to be made. A "lumped-parameter" approach, wherein the entire source is treated as a single node, was used for this analysis. However, this approach was augmented with additional analysis so that the centerline temperature within a pressure-tube (location of maximum temperature) could also be calculated.

The analysis of the source thermal response is presented in the next chapter and the predicted temperature history of the source is summarized in Chapter 3. Finally, some concluding remarks are outlined in Chapter 4. 


\section{ANALYSIS OF THE SOURCE THERMAL RESPONSE}

\subsection{Time-Dependent Decay Heat Within the Source}

It is assumed that at the time of the postulated accident, the source has undergone proton irradiation for a period of 1 year at $1.0 \mathrm{GeV}$ and $200 \mathrm{~mA}$. The decay-heat level at various times within the source as calculated from CINDER-90 calculations [2] is given in Table 2. These values for the decay heat correspond to a total of $24442 \mathrm{~kg}$ of Lead in the source rods. A least-squares fit of the numerical values in Table 2 yielded the following two equations for the time-dependent decay heat, $Q(t)$.

$$
\begin{aligned}
& Q(t)=\left[0.2474 \exp \left(-\frac{t}{1.240416}\right)+0.94407 \exp \left[-\frac{t}{198.1908}\right)+0.57753 \exp \left(-\frac{t}{11049.84}\right)\right] \cdot 10^{6} \\
& Q \text { in Watts, } t \leq 3600 s \\
& Q(t)=\left[0.11898 \exp \left(-\frac{t-3600}{8256.96}\right)+0.23866 \exp \left[-\frac{t-3600}{106722}\right]+0.05936 \exp \left(-\frac{t-3600}{2169144}\right)\right] \cdot 10^{6} \\
& Q \text { in Watts, } \quad t>3600 s
\end{aligned}
$$

Since the total decay heat is due to many different radionuclides decaying with different half lives, it was necessary to include more than one exponential term in the numerical model for the source decay heat.

\subsection{Thermophysical Properties and the Initial \\ Conditions for the Lumped-parameter Analysis}

In the lumped-parameter analysis presented in this report, the following values for various design and operating parameters for the APT SILC source have been used.

- Total mass of lead in the source: $24442 \mathrm{~kg}$

- Total mass of aluminum (cladding and shim rods) in the source: $1278.9 \mathrm{~kg}$

- Length of source rods, L: $2.12 \mathrm{~m}$

- Initial (normal operating point) centerline temperature within the source rods: $221.7^{\circ} \mathrm{C}$
Table 2. The Source Decay Heat.

\begin{tabular}{|l|c|}
\hline \multicolumn{1}{|c|}{$\begin{array}{c}\text { Time, } t \\
\text { (seconds) }\end{array}$} & $\begin{array}{c}\text { Decay Heat, } \mathbf{Q} \\
\text { (MW) }\end{array}$ \\
\hline 0 & 1.769 \\
\hline 1 & 1.625 \\
\hline 3 & 1.533 \\
\hline 10 & 1.475 \\
\hline 60 & 1.267 \\
\hline 180 & 0.952 \\
\hline 600 & 0.592 \\
\hline 3600 (1 hour) & 0.417 \\
\hline 10800 & 0.332 \\
\hline 36000 & 0.237 \\
\hline 86400 (1 day) & 0.167 \\
\hline 864000 & 0.040 \\
\hline 2592000 & 0.018 \\
\hline
\end{tabular}


- Nominal SPCS pump coastdown period: $45 \mathrm{~s}$

- Total mass of heavy water in the source (mass of heavy water in the bottom and top headers, and the mass of water adjacent to the source rods in the pressure-tubes): $5200 \mathrm{~kg}$

- Mass of water in the flooded source basin: $76665 \mathrm{~kg}$

- Total surface area of the source rods, $A_{\mathrm{g}}: 914.29 \mathrm{~m}^{2}$.

- Cross-sectional area for flow of heavy water through the source pressure-tubes, $\mathrm{A}_{\mathrm{w}}: 0.355 \mathrm{~m}^{2}$

The thermal conductivities and specific heats for lead, aluminum, and heavy-water are functions of temperature. However, for simplicity, and in view of the small changes in their values during the expected temperature variations, these properties have been assumed to be independent of temperature, and hence independent of time. The values used are summarized in Table 3.

Table 3. Thermophysical Properties of Aluminum, Lead, and $\mathrm{D}_{2} \mathrm{O}$ Used for the Calculations

\begin{tabular}{|c|c|c|}
\hline Material & $\begin{array}{c}\text { Thermal Conductivity, } \mathbf{k} \\
(\mathbf{W} / \mathbf{m K}) \text { [Reference] }\end{array}$ & $\begin{array}{c}\text { Specific Heat, } \mathbf{c}_{\mathbf{p}} \\
(\mathrm{J} / \mathbf{k g} \cdot \mathbf{K})\end{array}$ \\
\hline Aluminum & $237[3]$ & $995[3]$ \\
\hline Lead & $31.5[4]$ & $138[5]$ \\
\hline Heavy Water & $0.635[6]$ & $4200[7]$ \\
\hline $\mathrm{D}_{2} \mathrm{O}$ (vapor phase) & $0.0333[6]$ & Assume same as $\mathrm{H}_{2} \mathrm{O}$ vapor \\
\hline
\end{tabular}

By assuming steady state conduction through the source rods consisting of heat-generating lead rods with aluminum cladding, the average temperature of the "lumped" source during normal operation was calculated to be equal to $211.2^{\circ} \mathrm{C}$. This value is based upon a total power dissipation of $167.8 \mathrm{MW}$ and the centerline temperature of $221.7^{\circ} \mathrm{C}$ in the lead rods.

\subsection{The Pump Coastdown Period ( $\leq \mathrm{t} \leq 45 \mathrm{~s})$}

In this section, the source temperature is calculated as a function of time from the initiation of the LOCA to the end of the pump coastdown period ( 45 seconds). During this period the heavy-water will continue to flow through the pressure-tubes. Since the decay heat is only about $1 \%$ of the normal operating power, the source rods will actually cool during this period. Let $T_{8}$ be the average temperature of the source rods and $\mathrm{T}_{w i}$ be the heavy-water temperature at the inlet of the pressure-tubes. Under normal operation this temperature is equal to $60^{\circ} \mathrm{C}$. During the pump coastdown period, since the accumulator is discharging cold water (at $30^{\circ} \mathrm{C}$ ) into the bottom header of the source, it is assumed that the inlet water temperature, $\mathrm{T}_{w i}=0.5(60+30)=45^{\circ} \mathrm{C}$. The heat flux at the surface of the source rods, q" is given by: 


$$
q^{\prime \prime}=h\left(T_{s}-T_{w i}\right)
$$

where $h$ is the average heat-transfer coefficient on the surface of the source rods due to the flowing coolant in the pressure-tubes. At a time prior to the LOCA, based upon the normal operating power and the total surface area of the source rods, $q^{\prime \prime}=0.1835 \mathrm{MW} / \mathrm{m}^{2}$. Substituting $T_{s}=211.2^{\circ} \mathrm{C}$ and $T_{\text {wi }}$ $=60^{\circ} \mathrm{C}$ in the above equation, we obtain the normal operating value of the heat-transfer coefficient on the surface of the rods as:

$$
h_{0}=h(t=0)=1213.62 W / m^{2} K
$$

The nominal flow rate for each of the SPCS pumps is $6500 \mathrm{gpm}$. Assuming an exponential pump coastdown with a time constant of 10 seconds, the instantaneous pump flow rate for each of the pumps is given by:

$$
\text { Pump Flow Rate }=A_{w} u=0.41 \exp \left(-\frac{t}{10}\right), \quad m^{3} / s
$$

where $u$ is the average velocity of coolant in the pressure-tubes. For turbulent flow in tubes or on a flat plate, the Nusselt number $(=h \times$ Length/thermal conductivity of fluid $)$ is given by [8]:

$$
\text { Nusselt Number } \sim(\text { Reynolds Number })^{0.8} \Rightarrow h \sim u^{0.8}
$$

Therefore, it follows that:

$$
\left\{\begin{array}{c}
\frac{h}{h_{0}}=\left[\frac{\boldsymbol{u}}{u_{0}}\right]^{0.8} \\
o r, \\
h=h(t)=1213.62 \exp (-0.08 t) \quad W / m^{2} K
\end{array}\right\}
$$

The energy equation for the source rods yields the following differential equation for the source average temperature, $\mathbf{T}_{\mathbf{8}}$ :

$$
\left\{\begin{array}{c}
\frac{d T_{s}}{d t}=\frac{1}{M c p_{r}}\left[Q-h A_{s}\left(T_{s}-T_{w i}\right)\right] ; \quad \text { At } t=0, T_{s}=211.2{ }^{\circ} \mathrm{C} \\
T_{w i}=45^{\circ} \mathrm{C}, M c p_{r}=4.6455 \times 10^{6} \mathrm{~J} / \mathrm{K}
\end{array}\right\}
$$

where $\mathrm{Mcp}_{\mathrm{r}}$ is the total heat capacity (mass of lead $\times$ specific heat of lead + mass of aluminum $\times$ specific heat of aluminum) of all the source rods. The decay heat, $Q$ is given by Equation (1) and the total surface area of the source rods is equal to $914.29 \mathrm{~m}^{2}$. The above equation was solved by the fourthorder Runge-Kutta method using the "Mathcad" software. At the end of the pump coastdown period, the solution is: 


$$
\text { At } t=45 \text { seconds: } \quad T_{s}=62.2^{\circ} \mathrm{C}
$$

\subsection{Source Heat-Up From the End of the Pump Coastdown Till the Basin is Flooded $(45<t \leq 90 s)$}

During this time period, the source basin is assumed to be dry. Therefore, the source is heated adiabatically. Because there is no forced flow of water through the source following the end of the pump coastdown, the heat capacity of the heavy-water within the pressure-tubes also needs to be included in the lumped capacity model of the source. It is assumed that coolant in the bottom header of the source does not heat up. However, due to natural circulation, the water in the top header of the source will heat up. The "lumped source" is therefore assumed to consist of the source rods, the $D_{2} O$ adjacent to the source rods in the pressure-tubes, and the $\mathrm{D}_{2} \mathrm{O}$ in the top header of the source. The total mass of heavywater in the source is equal to $5200 \mathrm{~kg}$. The mass of heavy-water adjacent to the source rods is calculated to be equal to $820 \mathrm{~kg}$. Assuming that the balance of $(5200-820) \mathrm{kg}$ of coolant is equally split between the top and bottom headers of the source, the mass of $\mathrm{D}_{2} \mathrm{O}$ included in the lumped source is equal to $2190+820=3010 \mathrm{~kg}$. Therefore, the total heat capacity of the lumped source, $\mathrm{MCp} \mathrm{pl}_{\mathrm{l}}$ is given by:

$$
\begin{gathered}
\text { Lumped Source }=\text { Source Rods }+3010 \mathrm{~kg} \text { of } \mathrm{D}_{2} \mathrm{O} \text { in the Source } \\
\text { Heat Capacity of Heavy-water }=\mathrm{MCp}_{\mathrm{w}}=3010 \times 4200=12.64 \times 10^{6} \mathrm{~J} / \mathrm{K} \\
\text { Total Heat Capacity of Lumped Source }=\mathrm{MCp}_{\mathrm{ls}}=\mathrm{MCp}_{\mathrm{r}}+\mathrm{MCp}_{\mathrm{w}}=17.2875 \times 10^{6} \mathrm{~J} / \mathrm{K}
\end{gathered}
$$

The average temperature of the lumped source is then given by:

$$
\frac{d T_{s}}{d t}=\frac{Q}{M C p_{l s}} ; \quad \text { At } t=45 \mathrm{~s}: T_{s}=62.2^{\circ} \mathrm{C}
$$

where the decay heat, $Q$, is given by Equation (1). The solution of the above equation yields:

$$
\text { At } t=90 \text { seconds: } \quad T_{s}=65.47^{\circ} \mathrm{C}
$$

\subsection{Source Heat-Up to Saturation With Flooded Source Basin $(t>90 \mathrm{~s})$}

\subsubsection{Introduction}

At 90 seconds after the LOCA, the source basin will be flooded with cold water to a height which is at least above the top header of the source. This basin water serves as an additional sink for the source decay heat. As the source rods within the pressure-tubes heat up, some of the energy is transferred to the pressure-tubes which are immersed in the basin water on the outside. On the basin side, the pressuretubes transfer heat to the basin water via natural convection. Thus during this phase of the accident, the heat transfer from the source to the pressure-tube, and the heat transfer from the pressure-tubes to the 
basin water needs to be evaluated. As discussed in Section 1.2, it is assumed that the natural circulation in the unbroken loop (bulk flow of coolant through the source via the SPCS pump and SPCS heat exchanger) is not established. However, as discussed in sections 2.5.4 and 2.5.5, the source rods transfer heat to the pressure-tubes via conduction and natural convection (natural convection within each pressuretube, wherein the hot fluid from the central region rises upwards, and the cold fluid along the walls of the cold pressure-tube moves downwards).

The evaluation of the heat transfer from the source rods to the pressure-tubes is very involved. Therefore, the following four sub-sections present the details of the calculational procedure. Since this analysis uses an "effective thermal conductivity" model to evaluate the heat transfer from the source rods to the pressure-tubes, some general results for the case of "conduction through an infinitely long circular cylinder" are presented in the next section.

\subsubsection{Conduction Through a Long Circular Cylinder}

As shown in Figure 2, consider an infinitely long circular cylinder of diameter D with a uniform volumetric heat generation rate of $Q$ "' $\left(W / \mathrm{m}^{3}\right)$ within it. The heat produced within the cylinder is transferred to the surrounding fluid medium from the outside surface of the cylinder. If it is assumed that the heat-transfer coefficient, $h$, on the outside surface of the cylinder is uniform, then, the conduction heat transfer within the heat-generating cylinder is purely radial. For this case, it can be shown that the steadystate temperature distribution within the cylinder is given by:

$$
\left\{\begin{array}{c}
T(r)=T_{0}-\frac{r^{2}}{4 k} Q^{\prime \prime \prime} \\
T_{s}=\frac{1}{\pi R^{2}} \int^{R} 2 \pi r T(r) d r=T_{0}-\frac{R^{2}}{8 k} Q^{\prime \prime \prime} \\
T_{0}-T_{R}=\frac{R^{2}}{4 k} Q^{\prime \prime \prime}
\end{array}\right\}
$$

where $\mathbf{k}$ is the thermal conductivity of the cylinder material, $r$ is the radial coordinate, $R$ is the radius of the cylinder, $T(r)$ is the temperature at any radius $r, T_{0}$ is the temperature at the centerline, $T_{R}$ is the temperature at the outer surface of the cylinder, and $T_{s}$ is the average temperature of the cylinder. These equations will be used in the following sections.

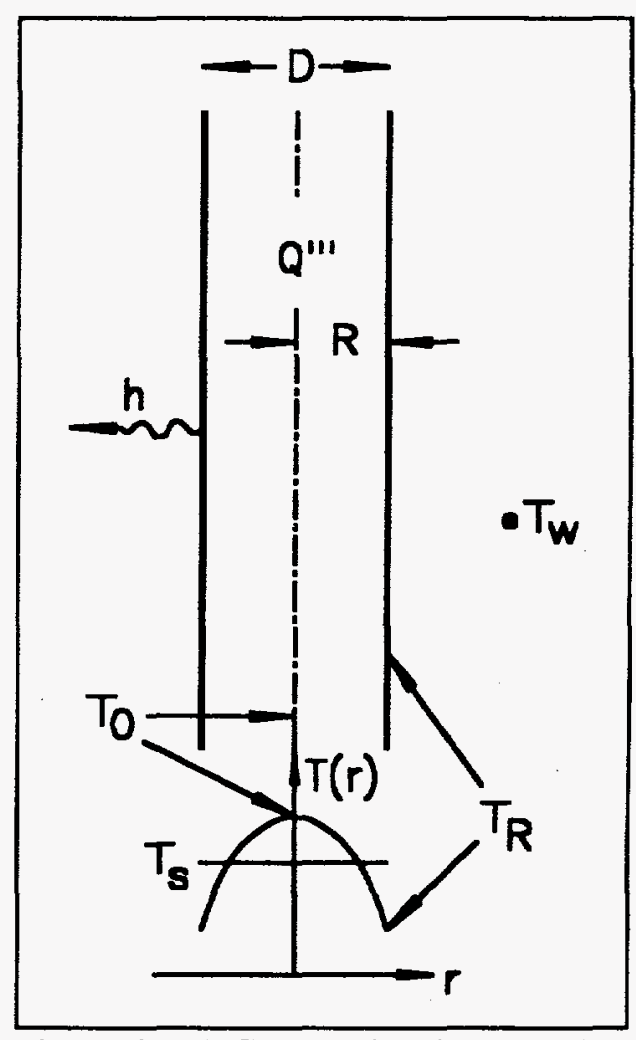

Figure 2. A Schematic of conduction through a heat generating cylinder.

\subsubsection{Effective Thermal Conductivity of a Single Source Rod}

The source rods consist of lead rods with thin aluminum cladding. As shown in Figure 3 , let $\mathbf{R}_{1}$ 
be the outer radius of the lead rod and $R_{2}$ be the outer radius of the aluminum cladding. Assuming a uniform volumetric heat source of Q" within the lead and aluminum, the differential equation governing the temperature distribution within the source rod is given by:

$$
\frac{d}{d r}\left(-k r \frac{d T}{d r}\right)=r Q^{\prime \prime \prime}
$$

Integration of the above equation from $r=0$ to $r=R_{1}$, and from $r=R_{1}$ to $r=R_{2}$ yields the following results:

$$
\left\{\begin{array}{c}
T_{0}-T_{2}=\frac{R_{2}^{2}}{4 k_{s r}} Q^{\prime \prime \prime} \\
\frac{1}{k_{s r}}=\frac{1}{k_{A l}}+\frac{R_{1}^{2}}{R_{2}^{2}}\left(\frac{1}{k_{P b}}-\frac{1}{k_{A l}}\right)
\end{array}\right\}
$$

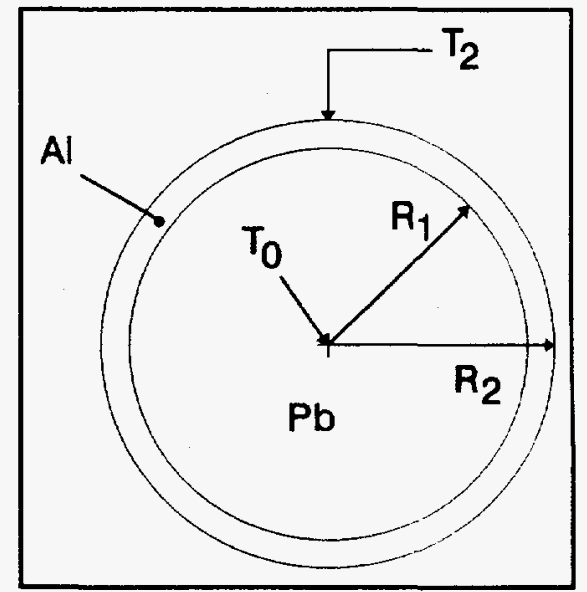

Figure 3. A cross section of the source rod.

where $T_{0}$ is the centerline temperature and $T_{2}$ is the temperature at the outside surface of the aluminum cladding. A comparison of the above equation with the last part of Equation (10) shows that $\mathbf{k}_{\mathrm{sr}}$ is the effective thermal conductivity of a single lead source rod with aluminum cladding. For source rods in Rows 4 and $5, R_{1}=0.00525 \mathrm{~m}$, and $R_{2}=0.00575 \mathrm{~m}$. Using the values of the thermal conductivities of lead and aluminum given in Table 3 , yields the following value for the effective thermal conductivity of a single source rod:

$$
\mathrm{k}_{\mathrm{sr}}=36.81 \mathrm{~W} / \mathrm{mK}
$$

\subsubsection{Effective Thermal Conductivity of Source Rods and the Surrounding Fluid Within a Pressure-Tube (Conduction Only)}

The pressure-tubes are densely packed with the source rods. During normal operation the space between the rods is occupied by heavy-water. If, during a loss-of-coolant accident, the heavy-water in the source should boil off, the space between the rods will be filled with steam $\left(\mathrm{D}_{2} \mathrm{O}\right)$. For the purpose of modeling the heat transfer from the source rods to the pressure-tube, the combination of the source rods and the surrounding fluid can be considered as a heat-generating medium with some effective thermal conductivity. In this section, an expression for the effective thermal conductivity of the source rods and the coolant for the case when there is no convective motion in the fluid will be derived.

A cross section of a pressure-tube in Row 3 of the source is shown in Figure 4. The source rods, with an outside diameter of $11.25 \mathrm{~mm}$, are arranged in a triangular pitch of $12 \mathrm{~mm}$. In order to enhance visualization, some of the source rods are shown as solid filled circles in this figure. As can be seen from this figure, the source rods can be viewed as a series of concentric hexagonal rings separated by the coolant $\left(\mathrm{D}_{2} \mathrm{O}\right)$. Therefore, for the purpose of modeling the conduction heat transfer through the interior of the pressure-tube, it will be assumed that heat is transferred from one ring to the next ring via one dimensional conduction through a fluid gap of constant thickness, $\delta$. In other words, a series 


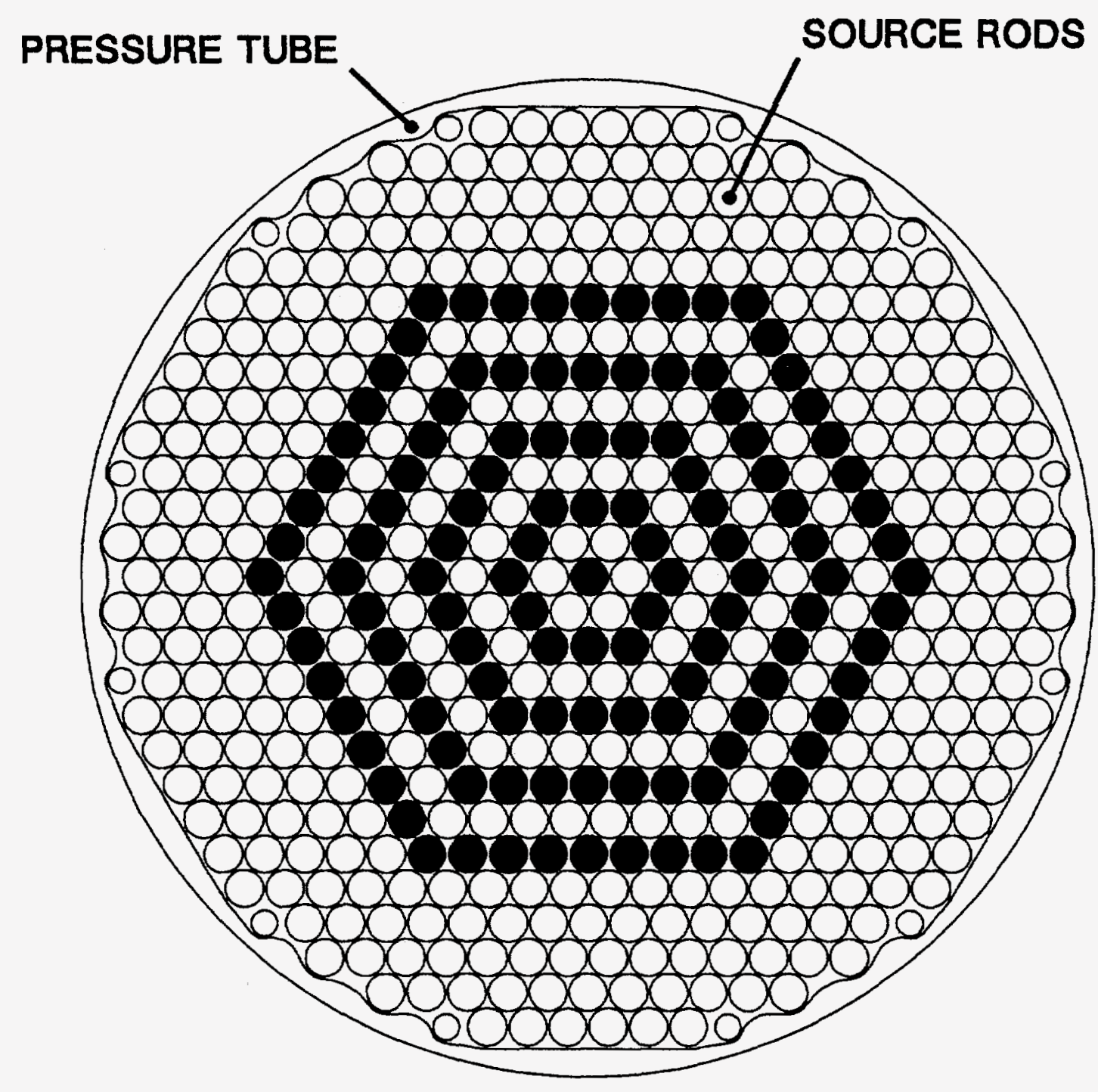

Figure 4. A cross-section of a pressure tube in Row 3. The outside diameter of the pressure tube is equal to $0.3 \mathrm{~m}$ and the diameter of the source rods is equal to $11.25 \mathrm{~mm}$. 
conduction model is being considered. This is more realistic and conservative than a parallel conduction model. Since the thermal conductivity of the source rods is much larger than that of heavy-water $\left(\mathrm{k}_{\mathrm{gr}} / \mathrm{k}_{\text {heavy water }}=36.81 / 0.635=57.96\right)$, the thermal resistance of the source rods as compared to the thermal resistance of the fluid gaps between the source rods, can be neglected.

A close-up of the center source rod and the surrounding source rods is shown in Figure 5. In this figure, $d$ is the diameter of the source rod, $p$ is the pitch between source rods, and $\delta$ is twice the minimum distance between adjacent rods. For the pressure-tubes in Row 3, $\mathrm{p}=12 \mathrm{~mm}$, and d $=11.25$ $\mathrm{mm}$. Therefore, $\delta=2(\mathrm{p}-\mathrm{d})=1.5 \mathrm{~mm}$. Although Rows 3, 4, and 5 each have the same number of source rods. (499), the rods in Rows 4 and 5 are larger in diameter. Thus the void fraction, or the fluid gap between the source rods, and consequently the thermal resistance of pressure-tubes in Rows 4 and 5 is smaller than that of the pressure-tubes in Row 3. Therefore, to be conservative, source rod dimensions for the third row will be used for the effective thermal conductivity calculations.

Let $\mathrm{q}_{\mathrm{r}}$ be the decay power produced in each of

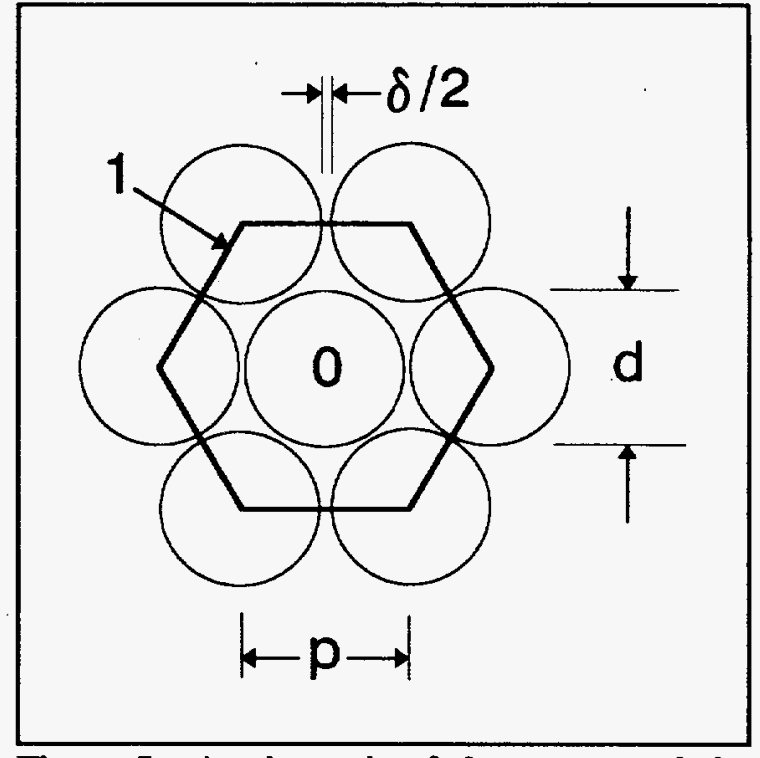

Figure 5. A schematic of the center and the surrounding source rods.

the source rods. Then, for steady-state conduction through the pressure-tube, the heat produced within a given hexagonal ring and all the rods enclosed by this ring must be transferred to the next outer ring via conduction across a fluid gap, whose average thickness is assumed to be $\delta$.

The zeroth ring is the center rod, and is marked 0 in Figure 5. The surface area across which the heat must be transferred to the next ring of surrounding rods is equal to $\pi \mathrm{dL}$, where $\mathrm{L}$ is the length of the source rods. The first ring consists of the six source rods surrounding the center rod. The surface area for heat transfer for this ring is assumed to be the part of the hexagon (marked as 1 in Figure 5) that lies within the source rods. Thus for the first ring, this is equal to $6 \mathrm{dL}$. The temperature of all source rods in a given ring is assumed to be the same, and is denoted by $T_{i}$, where $i$ is the ring index. Assuming a constant fluid gap of $\delta$ between each successive ring, an energy balance across the fluid gap between the center rod and the first ring gives:

$$
\left\{\begin{array}{l}
q_{r}=k \frac{T_{0}-T_{1}}{\delta} \pi d L, \text { or } \\
T_{0}-T_{1}=\frac{q_{r}}{k d L}\left(\frac{\delta}{\pi}\right)
\end{array}\right\}
$$

where $k$ is the thermal conductivity of the fluid within the pressure-tube. For energy transfer from the first ring to the second ring, the total power to be conducted is equal to $q_{r}+6 q_{r}=7 q_{r}$, and as 
discussed above, the surface area for energy transfer is $6 \mathrm{dL}$. Therefore, it follows that:

$$
\left\{\begin{array}{c}
7 q_{r}=k \frac{T_{1}-T_{2}}{\delta} 6 d L, \text { or } \\
T_{1}-T_{2}=\frac{q_{r}}{k d L}\left(\frac{7}{6} \delta\right)
\end{array}\right\}
$$

Similarly, for the energy transfer across the remaining fluid gaps we get:

$$
\begin{aligned}
& T_{2}-T_{3}=\frac{q_{r}}{k d L}\left[\frac{19}{12} \delta\right] \\
& T_{3}-T_{4}=\frac{q_{r}}{k d L}\left[\frac{37}{18} \delta\right) \\
& T_{4}-T_{5}=\frac{q_{r}}{k d L}\left(\frac{61}{24} \delta\right) \\
& T_{5}-T_{6}=\frac{q_{r}}{k d L}\left[\frac{91}{30} \delta\right) \\
& T_{9}-T_{10}=\frac{q_{r}}{k d L}\left(\frac{271}{54} \delta\right) \\
& T_{8}-T_{9}=\frac{q_{r}}{k d L}\left[\frac{217}{48} \delta\right) \\
& T_{7}-T_{8}=\frac{q_{r}}{k d L}\left(\frac{169}{42} \delta\right)
\end{aligned}
$$




$$
\begin{aligned}
& T_{10}-T_{11}=\frac{q_{r}}{k d L}\left(\frac{331}{60} \delta\right) \\
& T_{11}-T_{12}=\frac{q_{r}}{k d L}\left[\frac{397}{66} \delta\right) \\
& T_{12}-T_{13}=\frac{q_{r}}{k d L}\left(\frac{463}{66} \delta\right) \\
& T_{13}-T_{14}=\frac{q_{r}}{k d L}\left[\frac{499}{66} \delta\right]
\end{aligned}
$$

In the last equation above, $\mathrm{T}_{14}$ is the temperature of the pressure-tube wall. As noted earlier, in the above equations $k$ is the thermal conductivity of the fluid within the pressure-tube. By adding Equations (13) through (26), the temperature difference between the center rod and pressure-tube wall is obtained as:

$$
T_{0}-T_{14}=\frac{q_{r}}{k d L}(53.897 \delta)
$$

The above equation can now be used to determine the "effective thermal conductivity" of the pressuretube by comparing this result with that for the case of conduction through a heat-generating cylinder \{Equation (10)\}. Consider the source rods and the surrounding fluid in the pressure-tube to be a fictitious heat-generating medium with an effective thermal conductivity of $\mathbf{k}_{\text {eff. }}$ Since there are 499 source rods in the pressure-tube, the volumetric heat generation rate in the pressure-tube is given by:

$$
Q^{\prime \prime \prime}=\frac{499 q_{r}}{\pi R^{2} L}, \quad \text { where } R=\text { Radius of Pressure Tube }
$$

Substitution of this result in Equation (10) gives:

$$
T_{0}-T_{14}=\frac{R^{2}}{4 k_{e f f}} Q^{\prime \prime \prime}=\frac{R^{2}}{4 k_{e f f}} \cdot \frac{499 q_{r}}{\pi R^{2} L}
$$

From Equations (27) and (29), it follows that: 


$$
k_{\text {eff }}=\frac{499 d}{4 \pi \times 53.897 \delta} k=\frac{499 d}{4 \pi \times 53.897 \delta} k_{\text {fluid }}
$$

where $\mathrm{k}_{\text {fluid }}$, the thermal conductivity of the fluid in the pressure-tube, has been explicitly substituted for the symbol $\mathbf{k}$. Substituting the values of $\mathrm{d}(=11.25 \mathrm{~mm})$ and $\delta(=1.5 \mathrm{~mm})$, the effective thermal conductivity of the pressure-tube, for the case when there is no natural convection in the fluid, is obtained as:

$$
k_{e f f}=5.526 k_{\text {fluid }}
$$

Thus the effective thermal conductivity of the pressure-tube is 5.5 times the thermal conductivity of the fluid in the pressure-tube $\left(\mathrm{D}_{2} \mathrm{O}\right.$ liquid or vapor). When there is natural convection in the fluid within the pressure-tubes, the effective conductivity would be modified. As shown below, there is likely to be significant natural convection within the pressure-tubes.

Consider free convection in a rectangular vertical enclosure of width, W, height, $L$, and with adiabatic top and bottom surfaces. As shown in Figure 6, let the side walls of this enclosure be isothermal at temperatures $T_{1}$ and $T_{2}$. The Grashof number, $\mathrm{Gr}$ for this case is defined as:

$$
G r=\frac{g \beta\left(T_{1}-T_{2}\right) W^{3}}{\nu^{2}}
$$

where $\mathbf{g}$ is the acceleration due to gravity, $\beta$ is the coefficient of thermal expansion for the fluid in the enclosure, and $\nu$ is the kinematic viscosity of the fluid. In order to apply this case to that of a pressuretube, it is assumed that the distance between the two vertical plates is equal to one fourth of the diameter of the pressure-tube. That is, $W$ $=0.075 \mathrm{~m}$. Then, for $\left(\mathrm{T}_{1}-\mathrm{T}_{2}\right)=10{ }^{\circ} \mathrm{C}$, we get the following values for the Grashof number:

$$
\begin{aligned}
& \mathrm{Gr}=9.5 \times 10^{7}, \text { when fluid is Water } \\
& \mathrm{Gr}=2.8 \times 10^{5}, \text { when fluid is Steam }
\end{aligned}
$$

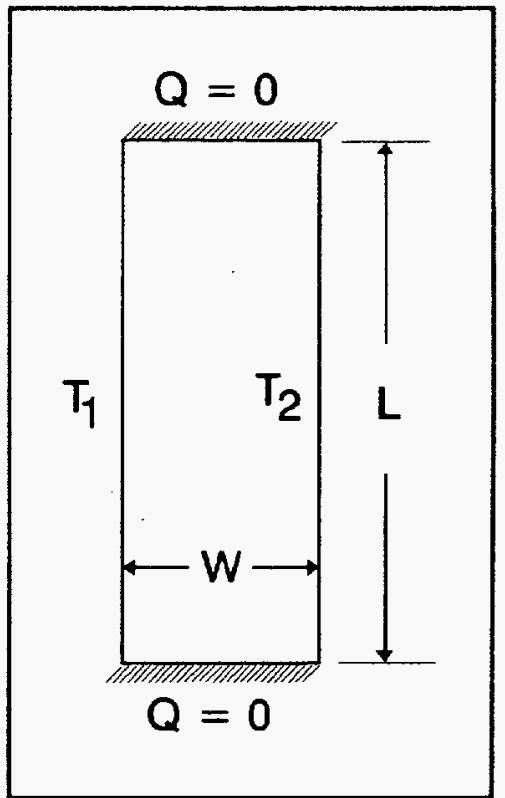

Figure 6. Definition Sketch for Natural Convection in a Vertical Cavity.

The critical value of the Grashof number for the onset of natural convection in vertical layers [8] is 8000 . Since the values obtained above are much larger than 8000 , natural convection is highly likely to occur within the pressure-tubes. Therefore, heat transfer due to natural convection may be significant, especially when the centerline temperature within the pressure-tube exceeds the boiling point of heavywater, which will enhance natural convection. 


\subsubsection{Effective Thermal Conductivity of Source Rods and the Surrounding Fluid Within a Pressure-Tube With Natural Convection Within the Pressure-Tubes}

In order to evaluate the heat transport from the source rods to the pressure-tube, heat-transfer correlations for the case of "natural convection in a cylindrical enclosure with heat-generating rod bundles" are needed. However, heat-transfer correlations for this case are not available. Clearly, experiments to determine these correlations are needed. Therefore, for the present purpose of obtaining a preliminary response of the APT SILC source to a large-break LOCA, the heat-transfer correlation for the case of "natural convection in a vertical cavity," as shown in Figure 6, is used. The correlation for the Nusselt number for this case is given by [9]

$$
N u=\frac{h W}{k_{\text {fluid }}}=\frac{k_{\text {eff }}}{k_{\text {fluid }}}=0.22\left[\frac{P r}{0.2+P r} R a\right]^{0.28}\left[\frac{L}{W}\right]^{-\frac{1}{4}}
$$

where $\mathrm{Nu}$ is the Nusselt number, $\mathrm{k}_{\text {eff }}$ is the effective thermal conductivity, $k_{\text {fluid }}$ is the thermal conductivity of the fluid in the pressure-tube, $\operatorname{Pr}$ is the Prandtl number of the fluid, and $\mathrm{Ra}$ is the Rayleigh number. The Rayleigh number is defined as:

$$
R a=\frac{g \beta\left(T_{1}-T_{2}\right) W^{3}}{\nu \alpha}
$$

where $\alpha$ is the thermal diffusivity of the fluid. In order to apply this correlation to the pressure-tube, it is assumed that $\mathrm{W}$, which is the horizontal distance between the two vertical walls of the cavity, is equal to one fourth of the pressure-tube diameter. Furthermore, $T_{1}$ is assumed to be equal to the average source temperature, and $T_{2}$ is the temperature of the pressure-tube wall.

\subsubsection{The case when pressure-tubes are full of (liquid) heavy-water}

Substitution of the dimensions of the pressure-tube and the properties of heavy-water in Equation (33) yields the following expression for the effective thermal conductivity of the pressure-tube:

$$
k_{\text {eff }}=11.58\left(T_{s}-T_{R}\right)^{0.28} k_{l} ; \quad \text { Temperatures in } K
$$

where $T_{g}$ is the average temperature of the source, $T_{R}$ is the temperature of the wall of the aluminum pressure-tube, and $k_{1}$ is the thermal conductivity of heavy-water in the liquid phase. It is noted that for $\left(\mathrm{T}_{\mathrm{s}}-\mathrm{T}_{\mathrm{R}}\right) \geq 0.072{ }^{\circ} \mathrm{C}$, the value of $\mathbf{k}_{\text {eff }}$ computed from Equation (35) above is always greater than that obtained for the case of pure conduction from Equation (31).

\subsubsection{The case when pressure-tubes are dry and filled with heavy-water vapor}

Consider the case when the heavy-water in the source has boiled off. In this case, the space between the source rods will be occupied by steam $\left(\mathrm{D}_{2} \mathrm{O}\right.$ vapor). Substitution of the properties of steam in Equation (33) for the case when $\mathrm{T}_{\mathrm{s}}=200^{\circ} \mathrm{C}$ and $\mathrm{T}_{\mathrm{R}}=100^{\circ} \mathrm{C}$, yields: 


$$
\mathrm{k}_{\mathrm{eff}}=4.0 \mathrm{k}_{\mathrm{ateam}}=4.0 \mathrm{k}_{\mathrm{v}}
$$

where $k_{v}$ represents the thermal conductivity of $D_{2} O$ vapor. But this is less than the effective conductivity for the case of pure conduction only, which is given by Equation (31) as: $k_{\text {eff }}=5.526 k_{\mathrm{v}}$. Hence, the convective heat-transfer correlation clearly underpredicts the effective thermal conductivity for the case when the pressure-tube is full of steam. Therefore, for this case the effective conductivity of the medium within the pressure-tube is assumed to the sum of "conduction" and "convection" conductivities as given by Equations (31) and (33) respectively. Since for steam, $\operatorname{Pr} \approx 1$, this yields:

$$
\frac{k_{e f f}}{k_{v}}=5.5+0.22\left[\frac{1}{1.2} \frac{g \beta W^{3}}{\nu^{2}}\right]^{0.28} \cdot\left(\frac{L}{W}\right]^{-\frac{1}{4}} \cdot\left(T_{s}-T_{R}\right)^{0.28}
$$

where $\mathrm{L}=2.12 \mathrm{~m}$, is the length of the source rods, $\mathrm{W}=\mathrm{D} / 4=0.075 \mathrm{~m}, \beta=2.19 \times 10^{-3} \mathrm{~K}^{-1}, \nu=$ $3.5 \times 10^{-5} \mathrm{~m}^{2} / \mathrm{s}$, and $\mathrm{k}_{\mathrm{v}}=0.0333 \mathrm{~W} / \mathrm{mK}$.

\subsubsection{Heat Transfer From the Pressure-Tubes to the Basin Water}

Pressure-Tubes transfer heat to the basin water via natural convection. The Nusselt number correlation for heat-transfer from a vertical surface due to natural convection is given by [5]

$$
\left\{\begin{array}{cc}
N u=\frac{h L}{k_{w}}=0.13(G r \operatorname{Pr})^{1 / 3} ; & 10^{9}<G r \operatorname{Pr} \leq 10^{12} \\
G r=\frac{g \beta\left(T_{s}-T_{w}\right) L^{3}}{\nu^{2}}, & \operatorname{Pr}=\frac{\nu}{\alpha}
\end{array}\right\}
$$

where $h$ is the average heat-transfer coefficient, $L$ is the height of the surface, $k_{w}$ is the thermal conductivity of the cooling fluid (basin water in our case), Gr is the Grashof number, $\alpha$ is the thermal diffusivity of the cooling fluid, and Pr is the Prandtl number of the cooling fluid. The temperature difference in the definition of the Grashof number is defined to be the difference between the surface temperature of the vertical surface and the bulk temperature of the cooling fluid. Since the present lumped-parameter model calculates only one average source temperature, $T_{g}$, this temperature is substituted in place of the pressure-tube wall temperature in the definition of the Grashof number in the above equation. For this reason, Equation (37) will overpredict the heat transfer rate to the basin water. Therefore, an alternative method, based upon the internal thermal resistance of the pressure-tube, is also used to evaluate the heat transfer to the basin water. This is discussed below.

The thermal resistance to heat transfer from the source rods to the basin water consists of two components: the thermal resistance internal to the pressure-tube as implied by the "effective conductivity" discussed in section 2.5.5, and the external thermal resistance between the outside surface of the pressuretube and the basin water implicit in Equation (37). To estimate the ratio of internal thermal resistance to the external thermal resistance, assume that the average source temperature, $\mathrm{T}_{\mathrm{g}}=65.47{ }^{\circ} \mathrm{C}$ and the basin water temperature, $T_{w}=30^{\circ} \mathrm{C}$. Substitution of these values in Equations (35) and (37) yields typical values for the effective thermal conductivity within the pressure-tube and the average heat-transfer 
coefficient on the basin side as, $k_{\text {eff }}=19.97 \mathrm{~W} / \mathrm{mK}$ and $\mathrm{h}=1151.8 \mathrm{~W} / \mathrm{m}^{2} \mathrm{~K}$. If $\mathrm{D}$ is the diameter of the pressure-tube, the ratio of the internal resistance to heat transfer and the external resistance to heat transfer is given by the Biot number, Bi as:

$$
B i=\frac{h D}{k_{\text {eff }}}=17.3>1
$$

Therefore, the thermal resistance within the pressure-tube is much larger than the external resistance to heat transfer. In other words, $h \rightarrow \infty$, which implies that the temperature of the pressure-tube can be assumed to be equal to the temperature of the basin water, $T_{w}$.

To find the "internal resistance limited" heat transfer to the basin water, the following approach is used. As shown in Figure 2, consider steady-state conduction in a heat-generating cylinder, consisting of a material with a thermal conductivity of $\mathbf{k}_{\text {eff }}$. This cylinder simulates the pressure-tube with heatgenerating source rods and $D_{2} O$. Even though the heat-transfer process in the source is transient, we shall assume that it is slow enough to be considered quasisteady. If $Q$ is the decay power within the source, only a fraction of this energy will be transferred to the basin water, the remaining energy simply increases the source temperature. Let $Q_{b}^{\prime \prime}$ " be the fictitious volumetric heat-generation rate $\left(W / \mathrm{m}^{3}\right)$ within the cylinder of Figure 2, such that its average temperature is equal to the average source temperature, $T_{s}$ and that its outside surface temperature is equal to the basin water temperature, $T_{w}$. Then, from Equation (10) it follows that:

$$
T_{s}-T_{w}=\frac{(D / 2)^{2}}{8 k_{e f f}} Q_{b}^{\prime \prime \prime}
$$

Therefore, the heat-transfer rate from the pressure-tubes to the basin water, $\mathrm{Q}_{\mathrm{basin}}$ is given by:

$$
Q_{\text {basin }}=V_{\text {tube }} Q_{b}^{\prime \prime \prime}=V_{\text {tube }} \frac{\left(T_{s}-T_{w}\right) 8 k_{e f f}}{(D / 2)^{2}} ; \quad k_{e f f} \text { from } E q(35) \text { or } E q(36)
$$

where $V_{\text {tube }}\left(=3.736 \mathrm{~m}^{3}\right)$ is the total internal volume of all the pressure-tubes. During the calculations, the heat transfer to the basin water is calculated both from Equation (40) above, and from Equation (37). Then, the minimum of the two values is used in the energy equations for the source and the basin water. As can be expected from the discussion in this section, it is Equation (40) that results in smaller of the two values.

Equation (10) can also be used to find the relationship between the average source temperature, $T_{s}$ and the centerline temperature within the pressure-tube, $T_{0}$ as:

$$
T_{0}=2 T_{s}-T_{w}
$$




\subsubsection{Energy Equations for the Source and the Basin Water}

The energy equation for the average lumped source temperature, $T_{g}$ is given by:

$$
\frac{d T_{s}}{d t}=\frac{1}{M C p_{l s}}\left[Q(t)-Q_{\text {basin }}(t)\right] ; \quad T_{s}=65.47^{\circ} \mathrm{C} \text { at } t=90 \mathrm{~s}
$$

where $Q(t)$ and $Q_{\text {basin }}(t)$ are the time-dependent decay heat and heat-transfer rate to the basin water, respectively. The total heat capacity of the lumped source, $M \mathrm{MCp}_{\mathrm{ls}}$ is given in Section 2.4.

The governing equation for the average temperature of the basin water, $T_{w}$ is given by

$$
\frac{d T_{w}}{d t}=\frac{1}{M C p_{b w}} Q_{b a s i n}(t) ; \quad T_{w}=30{ }^{\circ} \mathrm{C} \text { at } t=90 \mathrm{~s}
$$

where $\mathrm{MCp}_{\mathrm{bw}}$ is the total heat capacity of water in the basin. The flooded basin will contain $77 \mathrm{~m}^{3}$ of water and therefore, $\mathrm{MCp}_{\mathrm{bw}}=3.216 \times 10^{8} \mathrm{~J} / \mathrm{K}$.

Equations (42) and (43) were solved simultaneously by the fourth-order Runge-Kutta method using the Mathcad software. Computational results show that from $t=90 \mathrm{~s}$ to $t=3600 \mathrm{~s}$, the source actually cools from $65.47{ }^{\circ} \mathrm{C}$ to $55.09{ }^{\circ} \mathrm{C}$. During this time, the basin water was heated from $30^{\circ} \mathrm{C}$ to $36.28{ }^{\circ} \mathrm{C}$. Subsequently, the heat transfer to the basin water is no longer sufficient to remove all the decay heat from the source. As a result, both the basin water temperature and the average source temperature increase. The calculations were terminated when the average source temperature reached the saturation temperature $\left(101.42^{\circ} \mathrm{C}\right)$ for heavy-water at atmospheric pressure. The results at this time are:

$$
\mathrm{t}=82241.8 \mathrm{~s}=22.845 \mathrm{~h}: \quad \mathrm{T}_{\mathrm{s}}=101.42{ }^{\circ} \mathrm{C} \text { and } \mathrm{T}_{\mathrm{w}}=92.4{ }^{\circ} \mathrm{C}
$$

\subsection{Boil Off Half the Heavy-water Inventory in the Top Header of the Source}

After the source has reached the saturation temperature, the heavy-water in the source will begin to boil, and the level of heavy-water in the top header of the source will begin to decrease. During this period of boiling within the source, the average source temperature is assumed to be constant and equal to the saturation temperature. If $\mathrm{m}_{\mathrm{sw}}$ is the mass of source water boiled off at any time $\mathrm{t}$, then:

$$
\frac{d m_{s w}}{d t}=\frac{1}{h_{f g}}\left[Q(t)-Q_{\text {basin }}(t)\right] ; \quad m_{s w}=0 \text { at } t=82241.8 \mathrm{~s}
$$

where $h_{\mathrm{fg}}$ is the latent heat of evaporation for heavy-water. This equation was solved simultaneously with the differential equation for the basin water temperature (Equation (43) with $\mathrm{T}_{\mathrm{w}}=92.4^{\circ} \mathrm{C}$ at $\mathrm{t}=$ $82241.8 \mathrm{~s}$ ) until half of the heavy-water inventory in the top header of the source was boiled off. The results are:

$$
t=111828 \mathrm{~s}=31.063 \mathrm{~h}: \quad \mathrm{m}_{\mathrm{sw}}=1095 \mathrm{~kg} \text { and } \mathrm{T}_{\mathrm{w}}=99.12^{\circ} \mathrm{C}
$$




\subsection{Drain the Unbroken Loop}

It is assumed that after half the water in the top header has evaporated due to boiling, the level in the top header has dropped sufficiently to allow the "unbroken loop" (the SPCS loop on the left-hand side of Figure 1) to drain. Since the average temperature of source at the end of the pump coastdown period $\left(\mathrm{t}=45 \mathrm{~s}\right.$ ) was calculated to be $62.2^{\circ} \mathrm{C}$ in Section 2.3 , it is assumed that the temperature of water that drains into the source from the unbroken loop is $62.2^{\circ} \mathrm{C}$. Some of the water that drains into the source will drain directly into the top header and some will drain via the bottom header. As a result, it is assumed that the net effect of drainage of the unbroken loop is to replace the saturated heavy-water with the coolant at $62.2^{\circ} \mathrm{c}$. The new equilibrium temperature of the lumped source, $T_{\text {eq }}$, is therefore given by:

$$
M C p_{w}\left(T_{e q}-62.2\right)=M C p_{r}\left(101.42-T_{e q}\right)
$$

The heat capacities of the source rods and the heavy-water in the source are given in Sections 2.3 and 2.4 , respectively. The solution of the above equation is $\mathrm{T}_{\mathrm{eq}}=72.74{ }^{\circ} \mathrm{C}$. Therefore, after the unbroken loop has drained, the initial conditions for subsequent calculations are:

$$
\text { At } t=111828 \mathrm{~s}=31.063 \mathrm{~h}: \quad \mathrm{T}_{\mathrm{s}}=72.74{ }^{\circ} \mathrm{C} \text { and } \mathrm{T}_{\mathrm{w}}=99.12{ }^{\circ} \mathrm{C}
$$

\subsection{Reheat Source to Saturation}

Following the drainage of coolant from the unbroken loop, Equations (42) and (43) are again solved to compute the temperature history of the source and the basin water. At the beginning of the computation, since the source (at $72.74{ }^{\circ} \mathrm{C}$ ) is actually cooler than the basin water (at $99.12^{\circ} \mathrm{C}$ ), the heat is transferred from the basin water to the source. As a result of this, and the decay heat within the source, the source heats up rapidly. At 31.556 hours into the accident the source reaches saturation conditions. Thus, conditions at this time are:

$$
\text { At } \mathrm{t}=113601.6 \mathrm{~s}=31.556 \mathrm{~h}: \quad \mathrm{T}_{\mathrm{s}}=101.42{ }^{\circ} \mathrm{C} \text { and } \mathrm{T}_{\mathrm{w}}=98.36{ }^{\circ} \mathrm{C}
$$

\subsection{Boil off Heavy-water in the Source Pressure-Tubes}

At $t=113601.6 \mathrm{~s}$ the basin water temperature is still below the saturation temperature while the source is at saturation. Therefore, while the coolant in the source begins to boil off, the basin water will continue to heat up. As in Section 2.6, Equations (43) and (44) were solved simultaneously to determine the basin water temperature and the mass of source $\mathrm{D}_{2} \mathrm{O}$ boiled off as a function of time. The initial condition for the mass of source heavy-water boiled-off at $t=113601.6 \mathrm{~s}$ is: $\mathrm{m}_{\mathrm{sw}}=0$. The results are:

$$
\text { At } \mathrm{t}=134139 \mathrm{~s}=37.26 \mathrm{~h}: \quad \mathrm{m}_{\mathrm{sw}}=982.48 \mathrm{~kg} \text { and } \mathrm{T}_{\mathrm{w}}=100{ }^{\circ} \mathrm{C}
$$

Since at this time the basin water has reached saturation, and the temperature difference between the basin water and the average source temperature is small $\left(1.42{ }^{\circ} \mathrm{C}\right)$, the heat transfer to the basin water is neglected. All the decay heat in the source rods will result in the boiling of heavy-water in the source. 
The top header of the source contained a total of $2190 \mathrm{~kg}$ of heavy-water. Since $982.48 \mathrm{~kg}$ has already boiled off, this leaves the remaining $1207.52 \mathrm{~kg}$ of heavy-water to be boiled off in the top header. The time at which this will occur is given by:

$$
1207.52 \times h_{f g}=\int_{134139}^{t} Q(t) d t
$$

where $h_{f g}$ is the latent heat of evaporation of heavy-water. The solution to the above equation is time, $t=157078.99 \mathrm{~s}$. Therefore, at this time the heavy-water has boiled off just to the top of the source rods. Hence, an important intermediate result is:

$$
\text { Source-rod uncovery begins at } \mathrm{t}=157078.99 \mathrm{~s}=43.633 \mathrm{~h}
$$

The mass of heavy-water adjacent to the source rods is equal to $820 \mathrm{~kg}$. Substituting $820 \mathrm{~kg}$ instead of 1207.52 on the left-hand side of Equation (46) and changing the lower limit of the integral to 157078.99 in this equation yields: $t=174310.33 \mathrm{~s}$. Hence, at this time the source rods will be completely dry and the conditions of the source are:

$$
t=174310.33 \mathrm{~s}=48.42 \mathrm{~h} \text { : Source rods boiled dry, } T_{s}=101.42{ }^{\circ} \mathrm{C} \text {, and } T_{w}=100{ }^{\circ} \mathrm{C}
$$

\subsection{Source Heat-Up Following Dry-Out}

Following dry-out, the source rods will begin and continue to heat as long as the decaying time dependent decay heat is greater than the heat loss to the basin water. During this phase of the accident, it is the steam $\left(\mathrm{D}_{2} \mathrm{O}\right.$ vapor) that surrounds the source rods in the pressure-tubes. As discussed in Section 2.5.5.2, the source rods transfer heat to the pressure-tubes via combined conduction and natural convection, and the pressure-tubes in turn will transfer this energy to the basin water via nucleate boiling heat transfer since the basin water is already at saturation. Therefore, as long as the water level in the source basin is above the upper end of the source rods, the wall temperature of the pressure-tubes will remain virtually constant and only a few degrees above the saturation temperature. Since the bottom header is still full of water, some energy from the source rods (via natural convection from circulating hot steam) will also be transferred to the water in the pressure-tubes below the level of source rods. In order to evaluate this heat-transfer rate, it is assumed that the heat-transfer coefficient at the water interface below the source rods is equal to the heat-transfer coefficient on the inside surface of the pressure-tube. If $h$ is the heat-transfer coefficient, then, from Equation (40) it follows that:

$$
\left\{\begin{array}{c}
\frac{Q_{\text {basin }}}{N}=\pi D L h\left(T_{s}-T_{w}\right)=\frac{\pi(D / 2)^{2} L\left(T_{s}-T_{w}\right) 8 k_{e f f}}{(D / 2)^{2}} \\
o r, \\
h=\frac{8 k_{e f f}}{D}
\end{array}\right\}
$$


where $\mathbf{N}$ is the number of pressure-tubes. The effective conductivity, $\mathrm{k}_{\text {eff }}$ when the source rods are surrounded by steam is given by Equation (36). As discussed in Section 2.5.5.2, this equation also contains a conductive contribution of $5.5 \mathrm{k}_{\mathrm{v}}$ due to the radial conduction to the sides of the pressure-tube. Clearly, this contribution is not applicable for heat transfer to the water interface below the source rods. Therefore, neglecting this contribution to the effective conductivity, the heat-transfer coefficient at the water interface at the bottom of the pressure-tubes, $h_{b t}$ is given by:

$$
h_{b t}=\frac{8}{D}\left[0.22\left(\frac{1}{1.2} \frac{g \beta W^{3}}{\nu^{2}}\right]^{0.28} \cdot\left(\frac{L}{W}\right)^{-\frac{1}{4}} \cdot\left(T_{s}-T_{R}\right)^{0.28}\right] k_{v}
$$

where $T_{R}$ is temperature of the pressure-tube wall. For computation of the heat-transfer rate to the water surface below the source rods, this temperature and the temperature of the water surface, $T_{w s}$, is assumed to be equal to the saturation temperature of heavy-water $\left(101.42^{\circ} \mathrm{C}\right)$. The heat-transfer rate to the heavywater just below the source rods, $Q_{b t}$ is then given by:

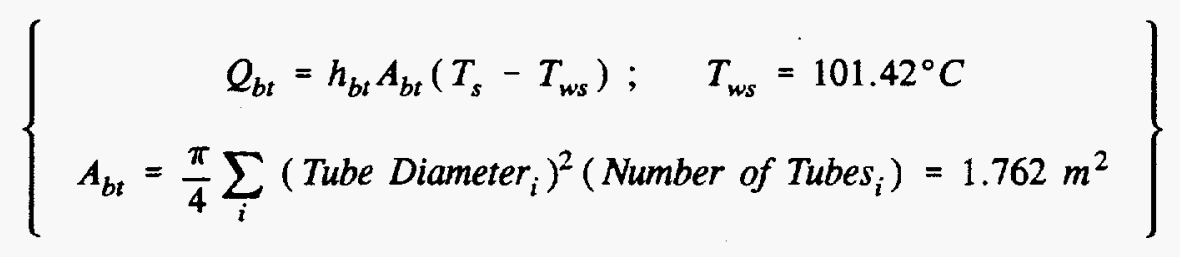

where $A_{b t}$ is the total interface area of the heavy-water just below the source rods. This heat transfer to the heavy-water below the source rods will result in the production of steam, which in turn, will flow through the array of source rods. It is therefore assumed that the steam exiting from top of the pressuretubes will be heated to the average temperature of the source rods.

The energy balance for the source rods yields the following equation for the average source rod temperature, $\mathrm{T}_{\mathbf{s}}$ :

$$
\frac{d T_{s}}{d t}=\frac{1}{M C p_{r}}\left[Q(t)-Q_{\text {basin }}(t)-Q_{b t}\left[1+\frac{\left(T_{s}-101.42\right) C p_{\text {steam }}}{h_{f g}}\right]\right]
$$

where $\mathrm{MCp}_{\mathrm{r}}$ is the total heat capacity of the source rods ( given in Equation (8)) and $\mathrm{cp}_{\text {steam }}$ is the specific heat at constant pressure for steam $(2000 \mathrm{~J} / \mathrm{kgK})$. The differential equations for the mass of basin water boiled off, $\mathrm{m}_{\mathrm{bw}}$, and the mass of water boiled off within the source, $\mathrm{m}_{\mathrm{sw}}$ are given by:

$$
\left\{\begin{aligned}
\frac{d m_{b w}}{d t} & =\frac{1}{h_{f g}} Q_{b a s i n} \\
\frac{d m_{s w}}{d t} & =\frac{1}{h_{f g}} Q_{b t}
\end{aligned}\right\}
$$

Equations (50) and (51) were solved simultaneously using the fourth-order Runge-Kutta method with the following initial conditions. At $\mathrm{t}=174310.33 \mathrm{~s}: \mathrm{T}_{\mathrm{s}}=101.42{ }^{\circ} \mathrm{C}, \mathrm{m}_{\mathrm{bw}}=0$, and $\mathrm{m}_{\mathrm{sw}}=0$. 
To calculate the centerline temperature within the pressure-tube, Equation (41) is used. It is assumed that the wall superheat of the pressure-tubes during nucleate boiling on the basin side is $10^{\circ} \mathrm{C}$. Therefore, the centerline temperature, $T_{0}$, which represents the maximum temperature within the pressure-tube is given by:

$$
T_{0}=2 T_{s}-110 ; \quad\left({ }^{\circ} \mathrm{C}\right)
$$

A plot of the calculated temperature history of the source will be presented in Chapter 3. The main results of the computations during this phase of the postulated accident are summarized below.

At $\mathrm{t}=181306.6 \mathrm{~s}=50.36$ hours:

$$
\begin{gathered}
\mathrm{T}_{\mathrm{s}}=218.7^{\circ} \mathrm{C}, \mathrm{T}_{0}=327.4^{\circ} \mathrm{C} \text { (Melting Point of Lead) } \\
\mathrm{m}_{\mathrm{bw}}=71.81 \mathrm{~kg}, \text { and } \mathrm{m}_{\mathrm{gw}}=1.18 \mathrm{~kg}
\end{gathered}
$$

At $t=206285.9 \mathrm{~s}=57.30$ hours:

$$
\mathrm{T}_{\mathrm{s}}=302.9^{\circ} \mathrm{C}
$$

The Average Source Temperature Attains a Maximum

At $t=259200 s=72$ hours:

$$
\mathrm{T}_{\mathrm{g}}=278.0^{\circ} \mathrm{C}, \mathrm{m}_{\mathrm{bw}}=2853.6 \mathrm{~kg} \text {, and } \mathrm{m}_{\mathrm{sw}}=49.3 \mathrm{~kg}
$$

At 50.36 hours into the accident, even though the average temperature of the source rods is well below the melting point of lead, the centerline temperature reaches the melting point of lead. From this time onwards the source rods at, and near the centerline of the pressure-tubes, will begin to melt. The molten material, if it gets out of the aluminum cladding, will fall into the bottom header of the source, and quench rapidly. However, the calculational model, represented by Equations (50) and (51) does not take this into account. This results in the over-prediction of the computed source-rod temperature. There are two reasons for this. First, as the inventory of the source-rod material within the pressure-tubes is reduced, the decay-heat power within the source is reduced. If this were taken into account, the calculated source-rod temperature would be lower. Secondly, as the molten source-rod material quenches in the bottom header, this will produce steam, which would then flow through the source-rod array, thereby providing additional cooling for the source rods.

The calculations also show that the average source-rod temperature reaches a maximum at $\mathbf{5 7 . 3}$ hours into the postulated accident, and that this peak temperature is $302.9^{\circ} \mathrm{C}$, which is well below the melting point of lead. At this time, the decay heat in the source rods is exactly balanced by the heat losses. Since the decay heat is continuously decreasing with time, the source-rod temperature subsequently decreases. 


\subsection{Estimation of the Mass of Molten Source-Rod Material Produced}

Since the calculations performed use a lumpedparameter model, and because the average temperature of the source rods remains well below the melting point of lead, the mass of source-rod material that would melt does not follow directly from the model. To circumvent this problem, the following approach, which is based upon the calculation of "excess enthalpy" above the melting point of lead within the pressure-tubes, is used. This excess enthalpy is calculated at the instant when the average source temperature reaches the maximum value.

From Equation (10), the temperature at any radius, $r$, within a pressure-tube is given by:

$$
T(r)=T(R)+\frac{Q^{\prime \prime \prime}}{4 k_{e f f}}\left(R^{2}-r^{2}\right)
$$

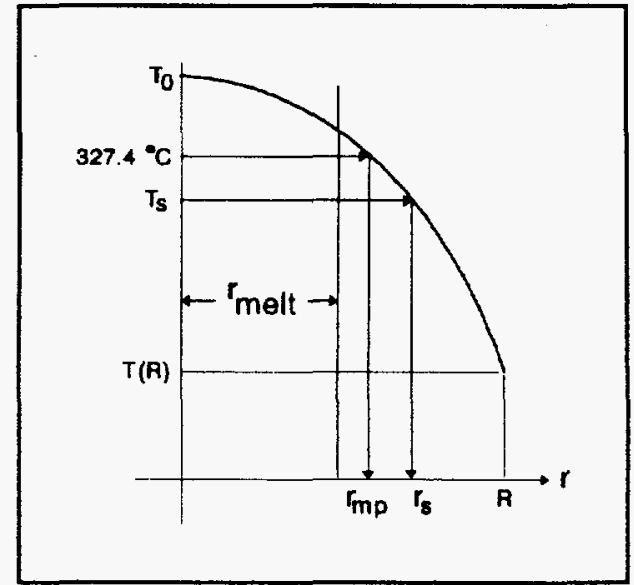

Figure 7. A schematic of temperature profile in the pressure-tube.

where $\mathbf{R}$ is the radius of the pressure-tube. This temperature distribution is schematically shown in Figure 7. As discussed in the last section, the peak average source temperature occurs at $t=57.3$ hours, and is equal to $302.9^{\circ} \mathrm{C}$. At this time, let $\mathrm{r}_{\mathrm{g}}$ be the radius at which the local temperature is equal to the average temperature, $\mathrm{T}_{\mathrm{s}}\left(=302.9^{\circ} \mathrm{C}\right)$, and let $\mathrm{r}_{\mathrm{mp}}$ be the radius at which the local temperature is equal to the melting point of lead $\left(327.4^{\circ} \mathrm{C}\right)$. Equation (10) also gives the following expression for the average temperature, $\mathrm{T}_{\mathrm{s}}$ within the pressure-tube:

$$
T_{s}=T(R)+\frac{R^{2}}{8 k_{e f f}} Q^{\prime \prime \prime}
$$

Then, from Equations (53) and (54) it follows that $r_{B}=R / \sqrt{2}$. As discussed in Section 2.10, the pressure-tube wall temperature, $T(R)$ is assumed to be equal to $110^{\circ} \mathrm{C}$. Using this value of $T(R)$, it can also be shown from Equations (53) and (54) that at the instant when $T_{\mathrm{s}}=302.9^{\circ} \mathrm{C}$,

$$
\left\{\begin{array}{c}
r_{m p}=0.66062 R \\
T(r)=T(R)+\frac{385.75}{R^{2}}\left(R^{2}-r^{2}\right) ; \quad \text { Temperatures in }{ }^{\circ} \mathrm{C}
\end{array}\right\}
$$

The above temperature distribution within the pressure-tubes can now be used to calculate the excess enthalpy beyond the melting point of lead in the pressure-tubes.

Since the temperature of all the source rods that lie in the domain $\mathbf{r}>r_{\mathrm{mp}}$, is less than the melting point of lead, these rods will not melt. However, since the latent heat of fusion is finite, not all of the source rods that are in the range $0 \leq r \leq r_{m p}$ will undergo melting. The excess enthalpy (beyond the melting point of lead) per unit length of the pressure-tube, $H$, for all the source rods up to $r=r_{m p}$ 
is given by:

$$
\frac{H}{\rho_{e f f}}=\int_{b}^{r_{m p}} C p_{P b-A l} 2 \pi r[T(r)-327.4] d r
$$

where $\mathrm{CP}_{\mathrm{Pb}-\mathrm{Al}}$ is the specific heat of the source rods and $\rho_{\text {eff }}$ is the effective density of the pressure-tube. Based upon the total mass of source rods and the total heat capacity of source rods as given in Sections 2.2 and $2.3, \mathrm{Cp}_{\mathrm{Pb}-\mathrm{Al}}$ is calculated to be $180.61 \mathrm{~J} / \mathrm{kgK}$. If $\mathrm{r}_{\text {melt }}$ is the radius up to which the source rods will melt, then, the above calculated excess enthalpy must be equal to the heat of fusion required to melt the source rods. Therefore, it follows that:

$$
\pi \mathscr{L}_{P b} r_{\text {melt }}^{2}=\frac{H}{\rho_{e f f}}
$$

where $\mathscr{L}_{\mathrm{Pb}}(=24.73 \mathrm{~kJ} / \mathrm{kg})$ is the latent heat of fusion for lead [10]. Substitution of Equations (55) and (57) in Equation (56) with $T(R)=110^{\circ} \mathrm{C}$, yields:

$$
\frac{r_{\text {melt }}^{2}}{R^{2}}=0.2683
$$

Therefore, $26.83 \%$ of the lead in the source pressure-tubes will melt. This corresponds to $6557.7 \mathrm{~kg}$ of lead. 



\section{A SUMMARY OF THE SOURCE TEMPERATURE HISTORY}

To recapitulate, in this accident scenario, a large double-ended break is assumed to occur in the cold leg above the basin. This is immediately followed by a successful beam trip, tripping of pumps, and the activation of the basin flood system. However, it is assumed that all active cooling systems fail. It is also postulated that no natural circulation (bulk flow through the pressure-tubes) in the unbroken SPCS loop takes place.

The calculated temperature history of the source is presented in Figure 8. As the coolant leaks from the primary system, the Accumulator and the Pressurizer begin to discharge their water inventories. The coolant (heavy-water) leaks from both ends of the break. The water discharged from the pressurizer flows directly through one end of the break without going through the source. Part of the Accumulator water discharged is circulated through the source pressure-tubes during the pump coastdown period, and the remaining flow is discharged from the other side of the break in the cold leg via the bottom header of the source. Since the decay heat at this time is only about $1 \%$ of normal power, the source rods actually cool during this pump coastdown period. It is calculated that at the end of the pump coastdown period (45 seconds), the source rods will cool to a temperature of $62.2^{\circ} \mathrm{C}$. By this time, it is calculated that the accumulator and the pressurizer will have drained, and the broken loop will be drained to the break location. However, due to the partial vacuum in the accumulator, the second loop will remain full of water. The source rods will begin to heat up after the pump coastdown flow has stopped. At 90 seconds after LOCA, the average source temperature is calculated to be $65.5^{\circ} \mathrm{C}$. The source basin will also be completely flooded with water at this time.

After the basin is flooded with cold water, the following mechanisms for the heat transfer from the source rods to the water in the basin are considered. The source rods transfer heat to the pressuretubes via conduction and natural convection (natural convection within each pressure-tube, wherein the hot fluid from the central region rises upwards and the cold fluid along the walls of the cold pressure-tube moves downwards). The pressure-tubes in turn, transfer energy to the basin water via natural convection. It is important to note that due to the extremely high thermal conductivity of the aluminum pressure-tubes, the thermal resistance of the pressure-tubes is negligible. Since all active cooling systems are presumed to fail, the water in the basin is therefore assumed to heat up adiabatically due to heat transfer from the source pressure-tubes.

Transient heat-transfer calculations show that from 90 seconds to 1 hour, the source continues to cool. Subsequently, owing to the smaller temperature difference between the source and the basin water, the heat transfer to the basin water is no longer sufficient to remove all the decay heat from the source rods. Therefore, the source temperature begins and continues to increase until it reaches the saturation temperature of $101.42^{\circ} \mathrm{C}$ at 22.8 hours. From this time onwards, the heavy-water within the source begins to boil off. At 31 hours into the accident, half the water inventory in the upper header is boiled off, and this is assumed to be sufficient to drain the "unbroken SPCS loop." This heavy-water inventory (at $62.2^{\circ} \mathrm{C}$ ) sweeps through the source pressure-tubes and the upper header rapidly, displacing the saturated water with the cold water from the unbroken loop. This results in the rapid cool-down of the source to $72.7^{\circ} \mathrm{C}$. However, the source re-heats back up to the saturation temperature at 31.6 hours.

Calculations show that at 37.2 hours the basin water is heated to $100^{\circ} \mathrm{C}$. Therefore, from this time forward the heat is transferred from the pressure-tubes to the basin water via boiling heat transfer. 
At 43.6 hours into the accident all of the $D_{2} \mathrm{O}$ inventory in the upper header of the source is boiled off and the source rods just begin to be uncovered. The heavy-water adjacent to the source rods continues to boil, and at 48.4 hours the source rods in the pressure-tubes are completely uncovered. Since the effective thermal conductivity of the source rods and steam is much less than that of the source rods and heavy-water, from this time onwards the source begins to heat up rapidly. At 50.4 hours into the accident, calculations show that while the average source temperature reaches $218.7^{\circ} \mathrm{C}$, the centerline temperature in the pressure-tubes reaches the melting point of lead $\left(327.4^{\circ} \mathrm{C}\right)$. Therefore, from this time forward, lead in the central regions of the pressure-tubes will begin to melt. Since the heat transfer from the source rods to the pressure-tubes is proportional to the temperature difference between the source and the pressure-tubes, calculations show that when the average source temperature reaches $302.9^{\circ} \mathrm{C}$, the heat transfer from the source rods to the pressure-tubes is exactly equal to the decay heat at this time. This occurs at $\mathbf{5 7 . 3}$ hours. Since the decay heat is continuously decreasing with time, consequently, the source rods begin to cool as the decay power diminishes with time. Calculations show that by this time $26.8 \%$ of the lead in the source rods will melt. The molten material will drop to the bottom header, freeze, and quench. Since beyond this time the average source temperature continuously decreases, the system is stable. Due to the design of the structures above the basin and the basin flood tank, all the steam produced due to the boiling of basin water is condensed and returned to the basin. Therefore, the basin will remain flooded. In addition, the calculations show that after 3 days only $2854 \mathrm{~kg} \mathrm{(3.7 \%} \mathrm{of} \mathrm{the} \mathrm{total}$ inventory) of the basin water will have boiled off. 


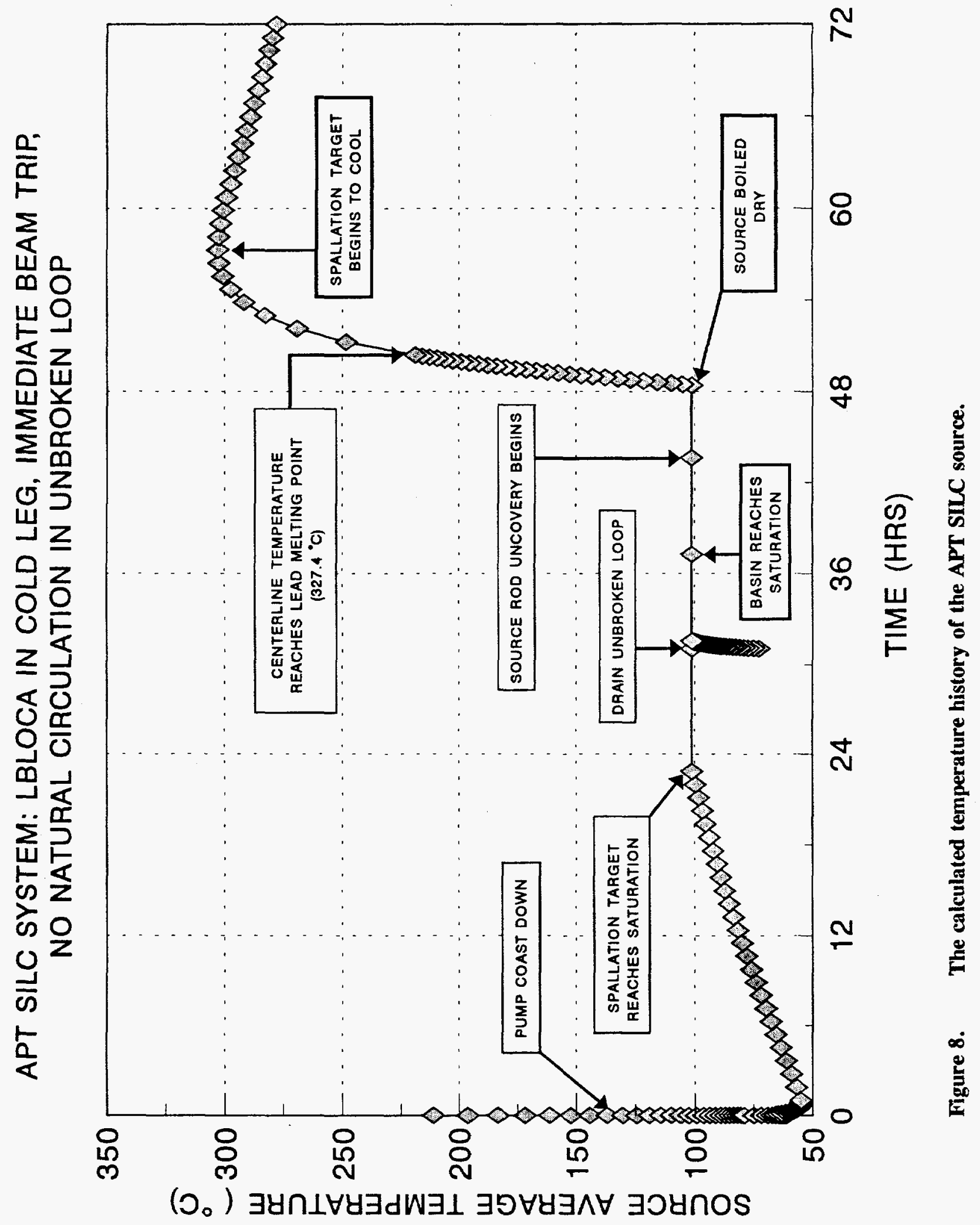





\section{CONCLUDING REMARKS}

A lumped-parameter approach has been used to predict the thermal response of the APT SILC source to a large-break LOCA. The accident scenario assumes the break to occur in the cold leg outside the source basin. The pipe break is immediately followed by the tripping of the proton beam and the activation of the source basin flood system. However, in order to be conservative, the accident scenario further assumes that all other (besides the Source Primary Coolant System) active cooling systems also fail, and that no natural circulation in the unbroken loop (the second primary coolant system loop) is established. These calculations for the above mentioned "beyond-design-basis event" were performed to support the Programmatic Environmental Impact Statement.

Calculations show that the source rods initially cool rapidly to a temperature of $62{ }^{\circ} \mathrm{C}$, and then heat slowly to the saturation temperature of $101.4^{\circ} \mathrm{C}$ at 23 hours after LOCA. Subsequently, the source rods remain submerged in boiling heavy-water till 44 hours. At this time, the source rods begin to be uncovered and at 48 hours into the accident the source rods are completely boiled dry. Although the average source temperature remains below the melting point of lead indefinitely, the centerline temperature reaches the melting point of lead at 50 hours after LOCA. The average source temperature continues to increase and reaches a maximum value of $303{ }^{\circ} \mathrm{C}$ at 57 hours. Thereafter, the source rods begin to cool since the heat transfer to the basin water is sufficient to remove all the decay heat from the source. It is expected that by this time approximately $27 \%$ of the lead inventory $(6558 \mathrm{~kg})$ in the source rods will melt. This molten material, assuming that the aluminum cladding also fails, will fall to the $\mathrm{D}_{2} \mathrm{O}$-filled bottom header, quench rapidly, and remain in a coolable state. 



\section{REFERENCES}

1. Van Tuyle, G. J., et al., "Topical Report on a Preconceptual Design for the Spallation-Induced Lithium Conversion (SILC) Target for the Accelerator Production of Tritium (APT)," Brookhaven National Laboratory Report, ATD/APT93-0025 (Rev.0), September 30, 1993.

2. Todosow, M., Private communication, June 1993.

3. Fink, J. K., et al., "Material Properties for HWR-NPR Severe Accident studies," Argonne National Laboratory Report, ANL/NPR-90/005, March 1990.

4. Holman, J. P., “Heat Transfer.” Seventh Edition, McGraw-Hill Publishing Company, p. 653, 1990.

5. McAdams, W. H., “Heat Transmission," Third Edition, McGraw-Hill Book Company, p. 461, p. $172,1954$.

6. "CRC Handbook of Chemistry and Physics," D. R. Lide, Editor, CRC Press, p. 6-9, 1990.

7. "Handbook of Chemistry and Physics," C. D. Hodgman, Editor, Chemical Rubber Publishing Co., p. 1884, 1951.

8. Kreith, F., "Principles of Heat Transfer," Second Edition, International Text Book Company, p. 314 , p. 348, p. $376,1966$.

9. "Eshbach's Handbook of Engineering Fundamentals," B. D. Tapley, Editor, John Wiley \& Sons, Inc., p. 10.59, 10.60, 1990.

10. "Chemical Engineer's Handbook," J. H. Perry, Editor, McGraw-Hill Book Company, p.3-108, 1963. 